\title{
Avanços nas pesquisas etnobotânicas no Brasil
}

\author{
Flávia Camargo de Oliveira ${ }^{1,2,5}$, Ulysses Paulino de Albuquerque ${ }^{3}$, Viviane Stern da Fonseca-Kruel ${ }^{4}$ e \\ Natalia Hanazaki
}

Recebido em 27/05/2008. Aceito em 12/03/2009

\begin{abstract}
RESUMO - (Avanços nas pesquisas etnobotânicas no Brasil). A Etnobotânica moderna é produto de mudanças históricas ocorridas dentro e fora da academia. O trabalho buscou traçar a trajetória dessa disciplina e suas tendências no Brasil. Para tal foi realizado um levantamento dos trabalhos, no período de 1968-2007, desenvolvidos por pesquisadores brasileiros no país e publicados nas revistas científicas de circulação nacional, internacional e em eventos nacionais. O artigo discute sobre o desenvolvimento da Etnobotânica e sobre a crescente valorização do conhecimento construído por populações não-industrializadas. Neste contexto destaca-se a influência das mudanças de interesses científicos e econômicos ao longo dos períodos avaliados e, especialmente, da implementação da Convenção sobre Diversidade Biológica. O desenvolvimento da Etnobotânica teve um impacto sobre a produção científica brasileira e refletiu em um notório incremento de trabalhos nesta área do conhecimento, porém ainda com predominância de estudos relacionados a plantas medicinais e/ou abordagens descritivas. Por fim, são tecidas algumas considerações sobre a atual situação da Etnobotânica no Brasil face às regulamentações legais determinadas pela Convenção sobre Diversidade Biológica.
\end{abstract}

Palavras-chave: América Latina, botânica econômica, conhecimento tradicional, etnobiologia, etnoecologia, histórico da etnobotânica

ABSTRACT - (Advances in ethnobotany research in Brazil). Modern Ethnobotany is a product of historical changes occurring inside and outside of the academy. The following article aimed to trace the trajectory and tendencies of Ethnobotany in Brazil. For this purpose, a review was performed of works which were developed by Brazilian researchers between 1968-2007, and published in scientific journals of either national or international scope and during national events. The article discusses the development of Ethnobotany and the increased value of the knowledge of non-industrialized peoples. In this context, the influences that stand out are changes in scientific and economic interests during the period evaluated and, especially, the implementation of the Convention on Biological Diversity. The development of Ethnobotany had an impact on Brazilian scientific production and caused a notable increase of works in this knowledge area, yet with the predominance of studies still regarding medicinal plants and/or descriptive approaches. Finally, we discuss the current situation in Brazilian Ethnobotany, in the context of the legal regulations determined by the Convention on Biological Diversity.

Key words: economic botany, ethnobiology, ethnobotany history, ethnoecology, Latin America, traditional knowledge

\section{Introdução}

A etnobotânica tem sido definida como "o estudo das inter-relações diretas entre seres humanos e plantas" (Ford 1978) em sistemas dinâmicos (Alcorn 1995).
Atualmente, esta disciplina abrange o estudo das interrelações das sociedades humanas com a natureza (Alcorn 1995; Alexiades \& Sheldon 1996). Seu caráter interdisciplinar e integrador é demonstrado na diversidade de tópicos que pode estudar, aliando os fatores culturais

\footnotetext{
1 Instituto de Pesquisas Cananéia-IPeC, sub-sede e base de apoio Cananéia, Rua Tristão Lobo 199, Centro, 11990-000 Cananéia, SP, Brasil

2 Universidade Federal de Santa Catarina, Departamento de Ecologia e Zoologia, Laboratório de Ecologia Humana e Etnobotânica, Campus Trindade, 88010-970 Florianópolis, SC, Brasil

3 Universidade Federal Rural de Pernambuco, Departamento de Biologia, Área de Botânica, Laboratório de Etnobotânica Aplicada, Rua Dom Manoel de Medeiros s.n., Dois Irmãos, 52171-900 Recife, PE, Brasil

4 Instituto de Pesquisas Jardim Botânico do Rio de Janeiro, Rua Pacheco Leão 915, 22460-040 Rio de Janeiro, RJ, Brasil

5 Autor para correspondência: flc_oliveira@yahoo.com.br
} 
e ambientais, bem como as concepções desenvolvidas por essas culturas sobre as plantas e o aproveitamento que se faz delas (Alcorn 1995; Albuquerque 2005). Neste sentido, especula-se que a origem da etnobotânica é coincidente com o surgimento da própria espécie humana, ou melhor, com o início dos primeiros contatos entre esta espécie e o Reino Vegetal (Schultes \& Reis 1995). Esta é uma noção de etnobotânica que a toma como algo próprio de uma cultura ou sociedade.

A etnobotânica é uma disciplina científica relativamente nova que não tem sido sistematizada e formalizada como outras ciências já estabelecidas (Hamilton et al. 2003). Entretanto, tem sido praticada por muitos cientistas que a valorizam e a reconhecem como tendo um papel relevante no desenvolvimento dos povos (Hamilton et al. 2003). Na realidade, pode-se dizer que a etnobotânica é antiga em sua prática, mas jovem em sua teoria, já que ela não é tão recente quanto se pensa, pois diferentes estudos demonstram que sua história remonta às relações entre os seres humanos e as plantas, e aos domínios da botânica aplicada e da etnografia botânica (Balick \& Cox 1996; Hamilton et al. 2003).

A pesquisa etnobotânica cresceu visivelmente na última década em muitas partes do mundo, em especial na América Latina e, particularmente, em países como o México, a Colômbia e o Brasil (Hamilton et al. 2003). O trabalho de Martínez-Alfaro (1994) ilustra o interesse que o tema vem despertando na comunidade científica latinoamericana, entretanto esse autor ressaltou que $52 \%$ dos artigos publicados em periódicos internacionais foram desenvolvidos na América Latina por pesquisadores norteamericanos, ingleses e franceses. Neste levantamento a América do Sul havia produzido $41 \%$ dos estudos de toda a América Latina, sendo que a maior parte deles foram desenvolvidos por pesquisadores nacionais dos seguintes países: Uruguai (100\%), Argentina (90\%), Chile (78\%), Brasil (67\%) e Paraguai (61\%).

Neste contexto, torna-se essencial olhar para a trajetória da Etnobotânica a fim de entender o desenvolvimento da disciplina no Brasil e refletir sobre os rumos tomados pelos estudos na área, com uma maior ênfase no ponto de vista das ciências biológicas. No caso do Brasil, e de outros países em desenvolvimento, a construção e a transformação da etnobotânica acontece em um cenário de diversidade cultural (envolvendo os conhecimentos e práticas de seus habitantes) e de diversidade biológica, que constituem um patrimônio de imenso valor potencial, incluindo plantas de interesse e potencial de mercado que podem ser possíveis fontes de geração de renda com sustentabilidade ambiental.

A história acadêmica desta disciplina se confunde com a história da Botânica e de outras áreas de estudos das ciências naturais e sociais, especialmente a
Antropologia. A etnobotânica apresenta fases que podem ser distinguidas conforme os interesses vigentes em cada época com relação ao conhecimento sobre plantas, detidos por diferentes sociedades e, conseqüentemente, conforme os direcionamentos dados aos estudos (Davis 1995; Clément 1998). Nos séculos XVIII e XIX, o interesse que predominava entre as sociedades industrializadas (também chamadas de ocidentais e "civilizadas") com relação ao conhecimento sobre sociedades mais isoladas ou não-industrializadas, era restrito aos benefícios econômicos que poderiam ser obtidos a partir desse conhecimento (Davis 1995; Clément 1998). Tais sociedades eram designadas como "aborígenes" e "primitivas" e o conhecimento que detinham era menosprezado, considerado como destituído de valor por não possuir um caráter científico (Clément 1998). Vale lembrar que se tratava de uma época na qual a ciência estava dando seus primeiros passos, e a negação do valor do conhecimento produzido fora da academia foi conveniente no sentido de afirmar a hegemonia do conhecimento científico (Clément 1998).

Segundo Clément (1998) há como traçar um paralelo entre a história da Etnobiologia e o da Etnobotânica. O autor propõe três períodos, separados por grandes mudanças de interesses direcionando as pesquisas na área da Etnobiologia (Clément 1998), sendo eles: o período pré-clássico, estendendo-se de meados do século XIX até a década de 1950; o período clássico, que vai da década de 1950 à década de 1980; e, por fim, o período pós-clássico, no qual, de acordo com Clément (1998), encontram-se os estudos etnobiológicos atuais.

Os primeiros passos da disciplina dentro do universo acadêmico começam a ser dados durante o período clássico, incluindo discussões sobre seus objetivos e metodologias. Nesta época, os estudos que hoje definimos como etnobotânicos eram designados por diversos nomes: botânica, botânica aplicada, botânica aborígene, etnografia botânica, sabedoria popular sobre plantas (plant lore) e etno-botânica, este último termo referindo-se a uma "botânica aplicada à etnologia" (Clément 1998).

Foi no final do século XIX que o termo "Etnobotânica" apareceu pela primeira vez no meio acadêmico: pesquisadores da área são unânimes na atribuição da autoria do termo ao botânico John W. Harshberger (Schultes \& Reis 1995; Clément 1998). Em 1896, o termo aparece em artigos científicos nos quais Harshberger discorre sobre a construção de um museu com objetos aborígenes, e sobre os objetivos básicos da Etnobotânica (Harshberger 1896; Clément 1998). No mesmo ano em que foi publicado o artigo de Harshberger, foi publicado também o artigo - "A contribution to ethnobotany" (Fewkes 1896) que faz referência à 
disciplina, já utilizando o termo "Etnobotânica".

A partir deste contexto, o presente estudo objetivou traçar um panorama sobre o desenvolvimento da etnobotânica no Brasil, a partir de fontes documentais, e avaliar os principais eventos e acontecimentos históricos que contribuíram com as mudanças e os avanços desta disciplina no país. Para refletir sobre o desenvolvimento da Etnobotânica no Brasil foi realizado um extenso levantamento na Base de Dados Plataforma Lattes, do Ministério de Ciência e Tecnologia (MCT)/Conselho Nacional de Desenvolvimento Científico e Tecnológico $(\mathrm{CNPq})$, uma vez que esta base apresenta informações atualizadas com Curriculum Vitae (CV) dos pesquisadores brasileiros, bem como grupos de pesquisas que atuam no país. Nesta busca foram utilizadas as palavras chave "Etnobotânica" e "Plantas Medicinais".

Tendo em vista que este artigo adota um enfoque preponderantemente biológico, a despeito das importantes contribuições da antropologia em particular e das ciências humanas como um todo, para complementar as informações foram realizadas buscas nas publicações da Sociedade Botânica do Brasil (SBB/ Comissão de Etnobotânica), bem como da Sociedade Brasileira de Etnobiologia e Etnoecologia (SBEE). Foram acessados os Anais de todos os Congressos Nacionais de Botânica que ocorreram entre os anos de 1985-2007 e os Anais dos seis Simpósios da SBEE realizados, desde 1996. No caso dos Congressos Nacionais de Botânica também foi realizada uma análise mais geral com relação aos eventos realizados durante o período de 1968-1985, porém não foi possível acessar todos os Anais produzidos neste período. Foi também efetuada uma análise do histórico dos trabalhos desenvolvidos por pesquisadores brasileiros no país e publicados em revistas científicas de circulação nacional ou internacional indexadas, no período de 1990 a 2007. As ferramentas de busca utilizadas foram: (http://scholar.google.com.br), ScienceDirect (http://www.sciencedirect.com), Scirus (http://www.scirus.com), Scopus (http://www.scopus.com) e WebSPIRS5 (http://web5s.silverplatter.com/webspirs). Foram incluídas nos resultados da busca publicações contendo pelo menos um pesquisador brasileiro entre os autores e que possuíam a palavra "etnobotânica" no título ou como palavra-chave. As palavras-chave utilizadas foram: "Ethnobotany" e "Ethnobotany" combinada com "Brazil". Por um lado, é provável que alguns trabalhos tenham escapado a esta busca pelos seguintes motivos: 1) $O$ fato de os autores não empregarem o conceito de etnobotânica em seus trabalhos; 2) A existência de artigos publicados em periódicos não indexados pelos buscadores usados. Por outro lado, alguns trabalhos não foram incluídos, pois apesar de terem sido resgatados pelas palavras-chave da busca tratavam-se de estudos fitoquímicos ou farmacológicos com plantas medicinais.

\section{O cenário atual da Etnobotânica na América Latina: enfoque para o caso do Brasil}

Nas últimas décadas, a Etnobotânica experimentou um crescimento expressivo encontrando-se especialmente fortalecida em países da América Latina (Hamilton et al. 2003; Fonseca-Kruel et al. 2005). Em parte isto se deve à atuação do "Grupo Etnobotânico Latino-Americano" (GELA) (Hamilton et al. 2003). O México tem se destacado em termos de produção científica na área, identificado como o país da América Latina que mais tem publicado em revistas científicas internacionais (Hamilton et al. 2003).

No Brasil tal fato é notório, pois no levantamento realizado na Plataforma Lattes foram encontrados 469 Curriculum vitae $(\mathrm{CV})$ de pesquisadores relacionados à área de Etnobotânica com doutorado, $964 \mathrm{CVs}$ de pesquisadores relacionados à categoria da referida Plataforma como "demais pesquisadores" (ou seja, sem a titulação de doutor). Para a palavra-chave Plantas Medicinais, foram relacionados $2.631 \mathrm{CVs}$ de pesquisadores com nível de doutorado. Deve-se considerar, entretanto, que a etnobotânica é uma área de interface, assim como a área de estudos sobre "plantas medicinais" e, ainda que tenham sido verificadas sobreposições entre elas, certamente também existem pesquisadores que atuam na área de plantas medicinais, mas não na área de etnobotânica e vice-versa. É evidente a maior quantidade de massa crítica atuando no tema "Plantas medicinais", o que explica, em parte, a tendência de muitos estudos etnobotânicos estarem direcionados também para plantas medicinais.

O enfoque dos trabalhos etnobotânicos varia conforme a região onde são realizados. A realidade local de cada país, incluindo os tipos de ecossistemas que abrangem, apresenta forte influência no direcionamento das pesquisas (Hamilton et al. 2003). Os temas mais abordados em estudos etnobotânicos desenvolvidos em países da América Latina, em ordem de predominância, são: plantas medicinais; domesticação e origem da agricultura; arqueobotânica; plantas comestíveis; estudos etnobotânicos em geral; sistemas agroflorestais e quintais; uso da floresta; estudos cognitivos; estudos históricos; pesquisas realizadas em mercados (Martínez-Alfaro 1994).

Um fato que se destaca com relação ao cenário etnobotânico na América Latina é o grande número de pesquisas realizadas por pesquisadores estrangeiros. $\mathrm{O}$ Brasil, entretanto, encontra-se entre os países que possuem maior número de pesquisas realizadas por pesquisadores nacionais (Hamilton et al. 2003). 
Durante o período pós-clássico da Etnobotânica (Clément 1998) alguns acontecimentos importantes contribuíram com o desenvolvimento e fortalecimento da disciplina no Brasil. Entre eles destacam-se: a publicação da $1^{\text {a }}$ edição da "Suma Etnológica Brasileira" (Ribeiro 1987); a realização do I Congresso Internacional de Etnobiologia (1988) em Belém, PA, durante o qual foi fundada a Sociedade Internacional de Etnobiologia (ISE); a criação da Comissão de Etnobotânica da Sociedade Botânica do Brasil (CEB/SBB) durante o $46^{\circ}$ Congresso Nacional de Botânica (1995); a fundação da Sociedade Brasileira de Etnobiologia e Etnoecologia (SBEE) durante o I Simpósio Brasileiro de Etnobiologia e Etnoecologia (1996); a realização do I Workshop Brasileiro de Etnobotânica e Botânica Econômica durante o $47^{\circ}$ Congresso Nacional de Botânica (1996).

A Comissão de Etnobotânica da SBB e a SBEE têm desempenhado um papel importante na promoção de diferentes fóruns de debates durante os quais profissionais da área discutem sobre perspectivas, limitações, questões conceituais, teóricas e metodológicas e também sobre implicações políticas e sociais das pesquisas na área.

\section{A Etnobotânica em eventos de expressão nacional}

A Etnobotânica tem se fortalecido no meio científico brasileiro e isto pode ser verificado, por exemplo, através do crescente número de trabalhos apresentados nos últimos anos nos Congressos Nacionais de Botânica (CNB), envolvendo diferentes tópicos (Fonseca-Kruel et al. 2005). Nos Anais de CNBs consultados e avaliados no período de 1968 até metade da década de 1980, os trabalhos com alguma interface com a Etnobotânica pareciam não ter um lugar definido e eram alocados em áreas temáticas como: "Botânica Aplicada", "Preservação da Flora - Botânica Econômica", "Botânica Econômica" e "Fitoquímica e Plantas Medicinais e Tóxicas". A maioria tratava de plantas daninhas e plantas invasoras de culturas agrícolas de interesse econômico, de plantas ornamentais e de plantas medicinais. Vale lembrar da análise realizada por Clément (1998), comentada no início do texto, afirmando que nesta época ainda existe uma forte influência de interesses no âmbito da Botânica Econômica, a qual direcionou os primeiros trabalhos sobre uso e conhecimento de plantas. Porém, já começam a surgir estudos motivados por razões não econômicas.

Uma reflexão interessante que emerge da análise destes primeiros Anais remete ao fato de que, apesar de apresentarem diferentes propostas, a Etnobotânica e a Botânica Econômica compartilham lugares comuns desde que surgiram dentro e fora da academia. Ainda hoje, em muitos estudos, o limite entre as duas abordagens é difícil de ser estabelecido. Sem dúvida, os trabalhos iniciais refletem uma abordagem essencialmente descritiva, fortemente carregada pela idéia de registro e catálogo das plantas úteis de uma região, num esforço de reunir informações sobre novos produtos.

Todavia, no cenário mundial, trabalhos sobre sistemas de classificação de plantas realizados por populações nativas e as primeiras teorias sobre relações entre pessoas e plantas marcam a transição para uma nova fase da Etnobotânica, a qual Clément (1998) chama de período clássico. Neste período emergem enfoques êmicos nas pesquisas, perspectiva que aproxima a avaliação da realidade estudada ao ponto de vista das pessoas que vivem esta realidade (Posey 1987). São citados como pioneiros e inovadores neste tipo de trabalho Harold Conklin (Conklin 1955; Conklin 1957; Conklin 1962), partindo de estudos sobre a estrutura lingüística para o entendimento dos princípios de nomenclatura de folk; Berlin et al. $(1966 ; 1968 ; 1973)$ e Metzger \& Williams (1996) (Haverroth 1997).

Como contribuições da América Latina neste sentido, destacam-se alguns trabalhos realizados no Brasil no final do século XIX e início do século XX, os quais já traziam abordagens mais emicistas ao tratarem da língua e da botânica indígenas. Como referências são citados os trabalhos de Barbosa Rodrigues (1842-1909) e Thekla Hartmann (Haverroth 1997). O México também se destaca neste período histórico da Etnobotânica latinoamericana pela atuação do historiador mexicano Paso y Troncoso, tido como um dos pioneiros em estudos sobre a classificação botânica desenvolvida por populações não-industrializadas, ao argumentar, com base em registros históricos, que populações ancestrais no México haviam desenvolvido uma "ciência" botânica bastante refinada e comparável à ciência moderna, a partir da prática da observação (Clément 1998). A pesquisa etnográfica sobre uso de plantas no período pré-clássico de Clément (1998) restringe-se, em grande parte, a monografias contendo listagens de plantas úteis e compilações de seus usos, produzidas com base em registros feitos por exploradores, missionários e aventureiros que partiam da Europa e dos Estados Unidos para realizar descobertas em outras terras (Davis 1995; Clément 1998). Estas pesquisas iniciais foram bastante criticadas já que muitas das análises e interpretações realizadas e teorias desenvolvidas com base nestes registros careciam do contato direto com o objeto de estudo (Davis 1995; Clément 1998). O reconhecimento da importância da pesquisa de campo no desenvolvimento de teorias e interpretações mais confiáveis sobre as sociedades estudadas revolucionou 
os estudos antropológicos e etnobotânicos (Davis 1995). Outra lacuna encontrada nas primeiras pesquisas envolvendo assuntos etnobotânicos é a falta de comunicação entre as disciplinas envolvidas, o que gerou registros bastante fragmentados. Botânicos careciam de um treinamento para a coleta de informações sobre o conhecimento a respeito das plantas investigadas. Ao mesmo tempo, investigações envolvendo conhecimento e uso de plantas realizadas por antropólogos da época não traziam informações relevantes sobre as espécies vegetais utilizadas; faltavam nestas pesquisas, por exemplo, amostras das plantas para fins de identificação (Davis 1995; Schultes \& Reis 1995; Clément 1998).

A partir do final da década de 1980, parece haver uma tentativa de separar os trabalhos de Etnobotânica e de Botânica Econômica dentro dos CNBs. Começam a aparecer estudos etnobotânicos mais direcionados para o entendimento das várias facetas das interações entre pessoas e plantas. Porém, ainda existe uma flutuação com relação às áreas temáticas nas quais são enquadrados os trabalhos, que pode estar em parte refletindo a ainda existente dificuldade em separar alguns dos estudos nessas duas áreas.

Em 1983, nos Anais do $34^{\circ} \mathrm{CNB}$, Ghillean T. Prance publicou um artigo referente à palestra que proferiu neste Congresso, no qual argumenta sobre a importância de se fazer pesquisas botânicas mais aplicadas, além das pesquisas básicas, com relação à flora amazônica, na busca de um equilíbrio entre conservação e utilização de recursos (Prance 1983). A partir desta data, nos Anais consultados, começam a aparecer resumos com preocupações características dos estudos etnobotânicos atuais como, por exemplo, padrões de interação entre populações tradicionais e plantas úteis (Amorozo \& Gély 1987) e manejo florestal realizado por populações tradicionais (Anderson 1987; Gély et al. 1987; Jardim \& Anderson 1987).

Neste ponto é importante refletir sobre os acontecimentos mais gerais relacionados aos estudos etnobotânicos. A busca pela estruturação teórica e metodológica da Etnobotânica, resposta às críticas recebidas até então (Albuquerque 2009), e as iniciativas de pesquisadores da área em aproximar os objetivos da Etnobotânica com o compromisso social da pesquisa científica, levaram a um amadurecimento da disciplina. As perspectivas atuais das pesquisas na área começaram a ser geradas a partir da metade do século XX. Muitas das mudanças verificadas desde então nos enfoques destas pesquisas são heranças de extensivos trabalhos pioneiros na região amazônica, realizados por etnobotânicos como R.E. Schultes e D. Posey a partir da década de 1940. Surgem, então, discussões sobre questões consideradas importantes e que começam a ser abordadas no domínio da Etnobotânica, tais como: a importância da interdisciplinaridade nos estudos (Prance 1991; Fonseca-Kruel et al. 2005), a valorização do conhecimento tradicional e a busca por soluções locais para problemas locais (perspectiva local) (Berkes et al. 1995; Martin 1995; Folke \& Berkes 1998; Pimbert \& Pretty 2000; Tuxill \& Nabhan 2001) e a relevância das metodologias quantitativas (Begossi 1996; Albuquerque 2005; 2009). É a partir do terceiro e último período, descrito por Clément (1998) como pós-clássico, que a Etnobotânica começa a se fortalecer no meio científico e a despontar como disciplina autônoma (Schultes \& Reis 1995). Nesta fase, os estudos etnobotânicos começam a busca pelo desenvolvimento de teorias e metodologias próprias e a apresentar interesses mais aplicados (Hamilton et al. 2003). Contudo, continuam fazendo parte dos objetivos da disciplina as tradicionais buscas nascidas nos campos da Botânica Econômica (originalmente praticada por botânicos) e das Etnociências (originalmente praticadas por antropólogos, lingüistas e etnólogos) (Clément 1998; Albuquerque 2005). A tendência para estudos fortemente descritivos, baseados em listas de espécies, ainda persiste no Brasil, apesar de começar a ser superada por estudos dotados de maior rigor e com questões e hipóteses de pesquisa bem delimitadas. O período pós-clássico, a partir dos anos 90, foi profícuo na produção de manuais de pesquisa como suporte metodológico para investigações na área (Martin 1995; Alexiades 1996; Albuquerque et al. 2008), fazendo-se sentir um avanço considerável na qualidade das abordagens.

Nos Anais dos CNBs do final da década de 1980 em diante, foi identificado o aparecimento de áreas temáticas denominadas de "Etnobotânica e Botânica Econômica", "Botânica Aplicada e Conservação", "Botânica Aplicada e Etnobotânica" e simplesmente "Etnobotânica" ou "Botânica Econômica". Estas áreas temáticas contemplam trabalhos etnobotânicos envolvendo perspectivas de valorização do conhecimento detido por populações tradicionais, trabalhos de Botânica Econômica e de conservação da natureza. No CNB realizado em 1995, em Ribeirão Preto, SP, a Etnobotânica deu um grande passo no meio científico brasileiro. Durante este Congresso foi formada a "Comissão de Etnobotânica" da Sociedade Botânica do Brasil (SBB). Para o Congresso realizado no ano seguinte, em Nova Friburgo, RJ, a recém formada comissão organizou o "I Workshop Brasileiro de Etnobotânica e Botânica Econômica", além das outras atividades relacionadas com estas áreas.

Apesar de existir uma valorização cada vez maior do conhecimento tradicional, reflexo inclusive da busca pela perspectiva emicista, é possível verificar entre os 
temas apresentados nos CNBs o aparecimento de trabalhos com populações urbanas, não-tradicionais, como por exemplo estudos realizados em quintais de zonas urbanas e em mercados públicos. Outra característica constantemente verificada em todos os CNBs nos quais foram apresentados trabalhos de Etnobotânica é o predomínio de trabalhos tratando de plantas medicinais. Estas duas tendências também são verificadas nos Simpósios Brasileiros de Etnobiologia e Etnoecologia, os quais serão comentados mais adiante.

Uma análise da trajetória da Etnobotânica nos CNBs entre 1985 e 2007 está apresentada na Fig. 1. Entre os anos 1985-1995 foi verificada certa estabilidade com relação ao número de trabalhos publicados nos CNBs envolvendo temáticas relacionadas à Etnobotânica. Já para o período seguinte, marcado pela atuação da Comissão de Etnobotânica da SBB (desde 1995 até a atualidade), verificou-se um crescimento expressivo no número de trabalhos etnobotânicos, com uma maior quantidade de trabalhos em 2006 (Fig. 1). Como já foi mencionado, os Anais consultados referentes aos congressos organizados a partir da década de 1980 trazem trabalhos etnobotânicos misturados a trabalhos de Botânica Econômica e, em alguns casos (CNBs de 1998 e 1999), áreas temáticas referidas como "Botânica Aplicada" traziam também trabalhos da área da conservação. Portanto, os dados não refletem exatamente a evolução exclusiva de Etnobotânica nestes congressos, mas mostram algumas tendências.

Assim como os CNBs, os Simpósios Brasileiros de Etnobiologia e Etnoecologia (SBEEs) permitem uma maior e melhor circulação de informações entre os pesquisadores etnobotânicos e têm contribuído para mudanças rápidas na área. Estes simpósios são realizados a cada dois anos e tiveram início em 1996, em Feira de Santana, BA. A Fig. 2 mostra a porcentagem e a quantidade em números absolutos de trabalhos

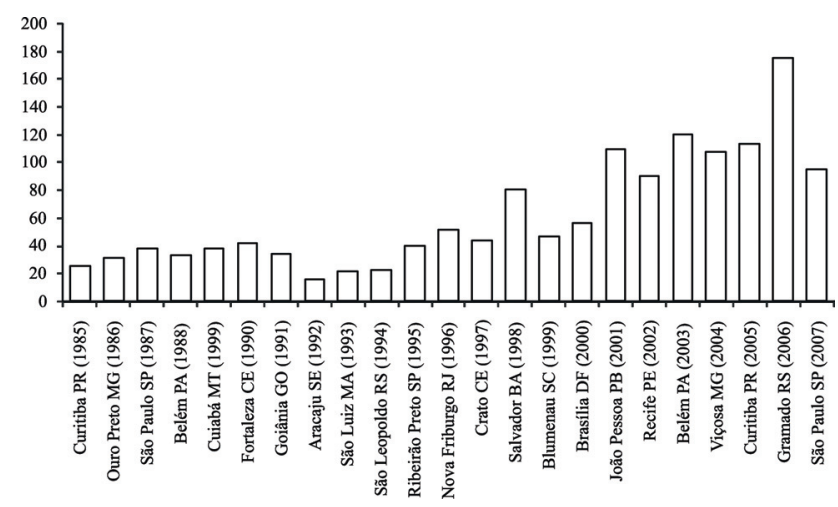

Figura 1. Trabalhos publicados nos Anais de Congressos Nacionais de Botânica em áreas relacionadas com a Etnobotânica no período de 1985-2007. etnobotânicos apresentados nestes simpósios. Para o V SBEE, de 2004, foi estabelecido o critério de classificar como trabalhos etnobotânicos todos os trabalhos que traziam a palavra "etnobotânica" no título ou nas palavras-chave, já que os Anais deste simpósio não trazem separação entre as áreas temáticas de trabalhos apresentados, como fizeram os anteriores.

De 1996 até 2004, a porcentagem de trabalhos etnobotânicos apresentados nos SBEEs diminuiu em

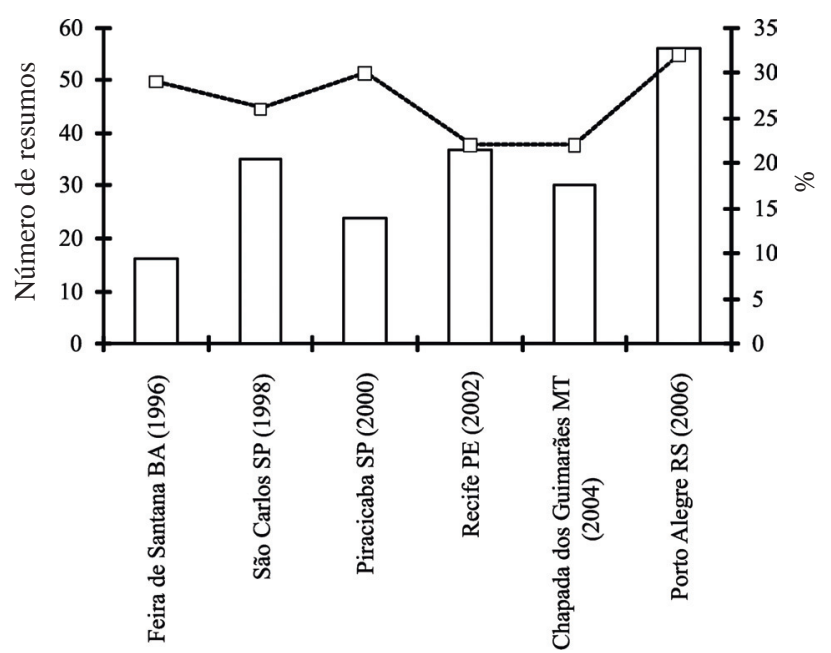

Figura 2. Porcentagem (pontos) e número absoluto (barras) de trabalhos publicados em Anais de Simpósios Brasileiros de Etnobiologia e Etnoecologia em áreas temáticas relacionadas com a Etnobotânica nos anos de 1996, 1998, 2000, 2002, 2004 e 2006.

relação à porcentagem de outros trabalhos também apresentados nestes eventos. Porém, quando se observa a quantidade em números absolutos percebe-se que os trabalhos etnobotânicos aumentaram desde o I Simpósio. Esta tendência pode estar mostrando um aumento e uma diversificação de temas abordados nos SBEEs durante este período, o que faz com que a porcentagem de trabalhos apresentados envolvendo o tema "Etnobotânica" diminua em relação aos trabalhos envolvendo outros temas. Nos Anais consultados, a área temática "Educação ambiental", por exemplo, apareceu pela primeira vez no IV Simpósio. Por fim, no último SBEE em 2006, houve um aumento expressivo do número de trabalhos publicados envolvendo a temática da Etnobotânica, os quais também aumentaram em termos de porcentagem em relação a outros temas.

\section{A etnobotânica em artigos científicos}

Com relação à busca por artigos envolvendo estudos etnobotânicos realizados no Brasil, para o ano de 1991, e para os anos anteriores a 1990 não foram encontradas publicações que se enquadrassem nas restrições 
estabelecidas para esta busca, descritas na metodologia deste trabalho. De acordo com os critérios de inclusão estabelecidos encontrou-se 185 trabalhos publicados no período de 1990 até 2007.

Os temas predominantemente abordados tratam exclusivamente de investigações sobre plantas medicinais, com aproximadamente 64\% das publicações (Elisabetsky \& Castilhos 1990; Brandão et al. 1992; Teixeira et al. 1992; Vieira \& Skorupa 1993; Di Stasi et al. 1994; Jacomassi \& Piedade 1994; Almeida et al. 1995; Baracho \& Agra 1995; Santos et al. 1995; Stehmann \& Brandão 1995; Albuquerque \& Silva-Soares 1996; França et al. 1996; Grob et al. 1996; Leal \& Elisabetsky 1996; Rocha \& Agra 1996; Amorozo 1997; Freire et al. 1997; Gilbert et al. 1997; Guarim Neto 1997; Pinheiro 1997; Arambarri \& Bayon 1998; Martins \& Gonçalves 1998; MeurerGrimes et al. 1998; Rodrigues 1998; Silva \& Andrade 1998; Teixeira et al. 1998; Bayon \& Arambarri 1999; Cataluña \& Rates 1999; Colares et al. 1999; Santos \& Elisabetsky 1999; Alves et al. 2000; Castellucci et al. 2000; Costa Neto \& Oliveira 2000; Knoss \& Falkenberg 2000; Mans et al. 2000; Santos 2000; Santos \& Sylvestre 2000; Schardong \& Cervi 2000; Simone et al. 2000; Albuquerque 2001; Castro \& Ferreira 2001; Dorigoni et al. 2001; Garlet \& Irgang 2001; Marodin \& Baptista 2001a;b; Parente \& Rosa 2001; Almeida \& Albuquerque 2002; Amorozo 2002; Araújo 2002; Begossi et al. 2002; Di Stasi et al. 2002; Ghedini et al. 2002; Holetz et al. 2002; Melo Júnior et al. 2002; Moreira et al. 2002; Peres et al. 2002; Rodrigues et al. 2002; Sangalli et al. 2002; Guarim Neto \& Morais 2003; Marçal et al. 2003; Oliveira et al. 2003; Shanley \& Luz 2003; Silva Filho et al. 2003; Cruz \& Kaplan 2004; Martins \& Oliveira 2004; Medeiros et al. 2004; Silva et al. 2004; Souza et al. 2004a; b; Almeida et al. 2005; Bueno et al. 2005; Di Stasi 2005; Fuck et al. 2005; Gazzaneo et al. 2005; Gurgel et al. 2005; Martins et al. 2005; Medeiros et al. 2005; Menezes et al. 2005; Napolitano et al. 2005; Negri et al. 2005; Pereira et al. 2005; Rezende \& Ribeiro 2005; Rodrigues \& Carlini 2005; Silva \& Albuquerque 2005; Vendruscolo et al. 2005(a); Andrade et al. 2006; Azevedo \& Silva 2006; Borba \& Macedo 2006; Franco \& Barros 2006; Monteiro et al. 2006; Oliveira et al. 2006; Pilla et al. 2006; Pimentel 2006; Pinto et al. 2006; Rodrigues \& Carlini 2006; Rodrigues \& Guedes 2006; Souza \& Felfili 2006; Vendruscolo \& Mentz 2006; Agra et al. 2007; Albuquerque e Oliveira 2007; Albuquerque et al. 2007(a); Albuquerque et al. 2007(b); Alves e Rosa 2007; Arjona et al. 2007; Cruz et al. 2007; Dickel et al. 2007; Giorgetti et al. 2007; Guerra et al. 2007; Leão et al. 2007; MaioliAzevedo e Fonseca-Kruel 2007; Marinho et al. 2007; Negrelle e Fornazzari 2007; Negrelle et al. 2007; Oliveira et al. 2007; Rodrigues 2007; Silva et al. 2007(a); Silva et al. 2007(b); Voeks 2007). Em alguns casos, as publicações envolvendo plantas medicinais não traziam apenas listagem de plantas e seus respectivos usos, mas também envolviam investigações sobre padrões de uso e manejo de recursos vegetais medicinais e/ou traziam contribuições metodológicas para a área.

As demais publicações trazem contribuições teóricas e metodológicas para a área e/ou abordam diversos aspectos das relações entre pessoas e plantas incluindo investigações sobre: conhecimento, uso e manejo de recursos vegetais em geral, significado cultural, origem e fluxo do conhecimento, etnotaxonomia e perda de conhecimento (Elisabetsky \& Wannmacher 1993; Figueiredo et al. 1993; Gottlieb \& Borin 1995; Begossi 1996; Hanazaki et al. 1996; Nunes \& Imamura 1996; Albuquerque 1997; Figueiredo et al. 1997; Second et al. 1997; Albuquerque \& Andrade 1998; Jardim \& Cunha 1998; Albuquerque 1999; Gottlieb et al. 1999; Rossato et al. 1999; Allem 2000; Begossi et al. 2000; Guarim Neto et al. 2000; Hanazaki et al. 2000; Peroni \& Martins 2000; Gottlieb et al. 2001; Marimon \& Felfili 2001; Sambatti et al. 2001; Siqueira \& Josafa 2001; Sousa et al. 2001; Albuquerque \& Andrade 2002a; b; Gottlieb \& Borin 2002; Gottlieb et al. 2002; Campos \& Ehringhaus 2003; Nappo et al. 2003; Souza \& Felfili 2003; Fonseca-Kruel \& Peixoto 2004; Shanley \& Rosa 2004; Silva \& Andrade 2004; Soares et al. 2004; Voeks \& Leony 2004; Zachia \& Irgang 2004; Albuquerque et al. 2005a,b; Albuquerque \& Lucena 2005; Basso et al. 2005; Bortolotto \& Guarim Neto 2005; Fonseca-Kruel et al. 2005; Mukherjee 2005; Pasa et al. 2005; Rocha \& Silva 2005; Shanley \& Rosa 2005; Silva \& Andrade 2005; Silva Filho et al. 2005; Vendruscolo et al. 2005(b); Botrel et al. 2006; Chaves \& Reinhard 2006; Costa et al. 2006; Cunha \& Albuquerque 2006; Ferraz et al. 2006; Hanazaki et al. 2006; Rodrigues 2006; Silva \& Andrade 2006; Silva et al. 2006; Souza et al. 2006; Baraloto et al. 2007; Florentino et al. 2007; Lucena et al. 2007; Miranda et al. 2007; Peroni et al. 2007; Schmidt et al. 2007).

Trabalhos com abordagens descritivas (no sentido adotado neste artigo), correspondem a $71 \%$ do total, contra aproximadamente $29 \%$ de artigos que sinalizaram com questões ou hipóteses explicitamente formuladas, ou incorporando técnicas quantitativas para análise dos dados. Esta última tendência é vista principalmente nas publicações mais recentes como uma resposta aos apelos de maior rigor e teste de hipóteses na pesquisa etnobotânica, mais fortemente sentidos a partir da década de 1990 (ver, por exemplo, Phillips \& Gentry 1993a; b; Albuquerque 2009). Vale ressaltar que para os trabalhos que envolvem análises químicas e/ou farmacológicas de plantas a abordagem etnobotânica utilizada foi considerada como descritiva, já que envolveu apenas o 
levantamento de possíveis plantas a serem investigadas.

O número de publicações de estudos etnobotânicos em revistas científicas, de acordo com as restrições estabelecidas para esta busca, experimentou um crescimento bastante expressivo nos últimos cinco anos, apesar de apresentar valores baixos em 2003 (Fig. 3). É importante lembrar que o levantamento bibliográfico não inclui revistas científicas que não se encontram indexadas e, portanto, não foram acessadas durante a busca. Porém, os resultados encontrados condizem com o histórico da disciplina no Brasil. Como o desenvolvimento acadêmico da disciplina no país é ainda jovem faz sentido concluir que deve ser recente o aparecimento das primeiras publicações realizadas por pesquisadores brasileiros. Da mesma forma que os temas explorados em pesquisas etnobotânicas aparecem mais numerosos e diversificados nos CNBs e SBEEs realizados nos últimos anos, o mesmo é esperado para as publicações em revistas científicas.

Os artigos encontrados refletem o padrão geral descrito anteriormente para os eventos científicos, bem como as discussões iniciadas no período clássico e consolidadas no período pós-clássico. A tendência para incorporar testes de hipóteses, discussões e análises críticas sobre metodologia, bem como o foco para a resolução de questões práticas, sem dúvida marcam um novo período para os estudos etnobotânicos no cenário mundial. O documento "Imperativos Intelectuais em Etnobiologia" deixa isso bem claro quando sugere que os projetos de pesquisa em etnobiologia devem ser guiados por hipóteses, que colaboradores apropriados devem ser incluídos para assegurar o rigor das metodologias provenientes de diferentes disciplinas e que a análise estatística e modelos matemáticos rigorosos e apropriados devem ser usados no delineamento da coleta e análise de dados (NSF Biocomplexity Workshop Report 2003).

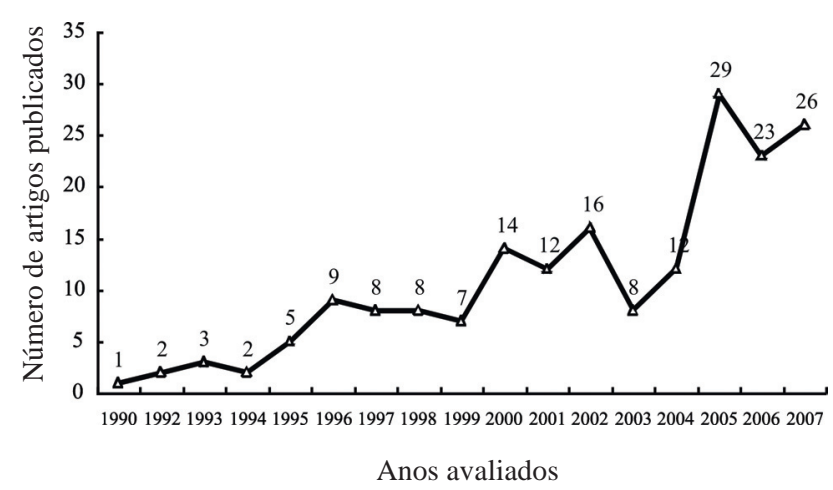

Figura 3. Trabalhos realizados no Brasil envolvendo estudos etnobotânicos, publicados durante o período de 1990-2007 em revistas científicas indexadas e contendo pelo menos um pesquisador brasileiro entre os autores.

\section{Considerações finais: a "ordem do dia" na Etnobotânica}

O conceito de Etnobotânica e as abordagens atuais surgem reformulados a partir das lacunas identificadas e das críticas levantadas à disciplina no seu período inicial (Davis 1995; Schultes \& Reis 1995; Clément 1998; Albuquerque 2005). Hoje em dia, estudos etnobotânicos podem enfocar tanto as sociedades industrializadas quanto as não-industrializadas, incluindo populações tradicionais e não tradicionais (Minnis 2000; Begossi 2001). Esses estudos variam desde aqueles que apresentam um caráter meramente filosófico, com um fim em si mesmos, passando pelos que envolvem interesses pelos aspectos psicológicos e cognitivos, relacionados às maneiras como pessoas pertencentes a sociedades não-industrializadas interpretam e tratam suas plantas úteis (Schultes \& Reis 1995), estendendo-se até estudos direcionados para resolver problemas de ordem prática e que fazem parte da chamada "Etnobotânica Aplicada" (Schultes \& Reis 1995; Cunningham 2000; Hamilton et al. 2003).

Dentre as preocupações da Etnobotânica Aplicada persistem as buscas por novos produtos oriundos de plantas para utilização na indústria (medicamentos, plantas alimentícias, espécies utilizadas para manufatura) com a predominância de pesquisas envolvendo plantas medicinais (Hamilton et al. 2003). Mas, também são acrescidas a estas preocupações questões de desenvolvimento humano, conservação da natureza, uso de recursos e ecossistemas e questões de segurança alimentar e saúde pública (Hamilton et al. 2003). Essas preocupações são notáveis em trabalhos produzidos nos países considerados "em desenvolvimento" (Hamilton et al. 2003) os quais concentram grande diversidade cultural e biológica ao mesmo tempo em que apresentam problemas de distribuição de terras, pobreza e fome (Pimbert \& Pretty 2000). São países onde a Etnobotânica surge imersa em questionamentos sobre suas perspectivas originais. O surgimento de uma Etnobotânica acadêmica renovada com relação aos seus objetivos e abordagens iniciais é bem descrito para o México onde crises políticas e sociais, aliadas à preocupação com a preservação da diversidade cultural e biológica deste país, contribuíram com o surgimento de estudos etnobotânicos aplicados conduzidos por pesquisadores preocupados com o papel social da Ciência (Toledo 1995).

No âmbito da conservação de recursos e ecossistemas fazem parte da "ordem do dia" da Etnobotânica os estudos voltados para a conservação de germoplasma in situ, incluindo a conservação de plantas em vários níveis - variedades, espécies, populações (Tuxill \& Nabhan 2001), e o desenvolvimento de 
estratégias de conservação biológica que possam também conciliar desenvolvimento humano e sobrevivência cultural (Minnis 2000). Dentre as tendências verificadas nesses estudos estão a crescente valorização de populações locais como parceiras (Berkes et al. 1995; Folke \& Berkes 1998; Tuxill \& Nabhan 2001; Hamilton et al. 2003; Seixas 2005) e as reflexões sobre o posicionamento de pesquisadores da área perante estas populações, comumente tratadas como meros objetos de estudos e "fontes de dados" das quais se extraem informações etnobotânicas (Hamilton et al. 2003). Neste contexto, abordagens de pesquisas participativas (Seixas 2005) têm ganhado espaço em estudos etnobotânicos comprometidos com questões de desenvolvimento humano aliadas à conservação da natureza. Estas abordagens de pesquisa partem do reconhecimento do direito destas populações em participar das decisões sobre a conservação dos ecossistemas nos quais estão inseridas, e de cujos recursos e benefícios são dependentes diretamente (Berkes et al. 1995; Folke \& Berkes 1998; Pimbert \& Pretty 2000; Tuxill \& Nabhan 2001; Seixas 2005).

A crescente valorização do conhecimento tradicional também proporcionou o surgimento de um interesse renovado nos possíveis benefícios econômicos oriundos de plantas, o qual transformou o próprio conhecimento em um tipo de produto valorizado economicamente e alvo da bioprospecção (Elisabetsky 2003). Por algum tempo foi sustentado que a busca por novos produtos oriundos de plantas traria benefícios para a humanidade em geral. Com base neste argumento afirmava-se que recursos vegetais e conhecimentos tradicionais associados deveriam ser considerados como patrimônios da humanidade e de livre acesso. A polêmica por trás desta afirmação está nas discrepâncias com relação à distribuição dos benefícios citados acima. Historicamente as partes beneficiadas concentram-se nos países mais ricos e desenvolvidos, os quais detêm a maioria das patentes de produtos da biotecnologia advindos de recursos naturais (por exemplo, medicamentos e sementes) e nos quais reside a maior parte da população que tem poder aquisitivo para acessar esses produtos (Cunha 1999). Já os países "em desenvolvimento", centros de diversidade biológica e cultural, tradicionalmente sempre foram explorados atuando como fornecedores de matéria-prima (recursos naturais e conhecimento tradicional associado) e permanecendo distantes dos produtos finais elaborados a partir desta matéria-prima (Cunha 1999; Hamilton et al. 2003).

A Etnobotânica atualmente enfrenta diversos desafios na busca de seu fortalecimento. Dentre as necessidades apontadas como mais urgentes neste sentido estão o estabelecimento de um diálogo eficiente entre as áreas que fazem interface nos estudos etnobotânicos, viabilizando estudos interdisciplinares de fato (Prance 1991); a implementação de cursos e programas de treinamento de profissionais da área; a troca de experiências com relação a resultados alcançados e metodologias utilizadas; o desenvolvimento de programas de monitoramento dos resultados de pesquisas enfocando conservação e uso sustentável de recursos, visando à confirmação de sua eficiência com base em evidências científicas e a importância de buscar maior rigor científico nas pesquisas (Hamilton et al. 2003). Para este último propósito, um caminho que vem sendo trilhado por muito pesquisadores é o uso de ferramentas quantitativas de coleta e análise de dados visando, por exemplo, a produção de dados comparáveis (Prance 1991; Hamilton et al. 2003; Albuquerque 2005).

Abordagens quantitativas de coleta e análise de dados são complementares às qualitativas e podem revelar informações que não são acessadas através de análises qualitativas e que podem ajudar a testar muitas hipóteses sobre manejo, uso e conservação de recursos.Por meio de técnicas quantitativas é possível realizar avaliações e comparações sobre o uso de plantas por área delimitada de terra por determinado grupo, sobre a importância das plantas dentro de certo contexto, sobre as famílias botânicas conhecidas e utilizadas e comparações entre formas de uso de plantas mais significativas (Albuquerque 2005). Em contrapartida, sem uma análise qualitativa e descritiva perdem-se muitas informações relevantes, as quais os números acabam escondendo ou não revelando. O uso conjunto de ferramentas qualitativas e quantitativas tem enriquecido em muito os trabalhos na área (Albuquerque 2005).

Outra preocupação com relação à condição atual da Etnobotânica no mundo e que tem sido abordada por alguns autores e em fóruns de debates diz respeito ao treinamento adequado de profissionais (Hamilton et al. 2003; Fonseca-Kruel et al. 2005). Este treinamento é considerado vital para o bom desempenho de trabalhos na área, principalmente numa época em que tem crescido o interesse pelas aplicações da Etnobotânica para resolver problemas delicados e de ordem prática. Para isto é importante a criação de cursos e programas de treinamento, especialmente em países "em desenvolvimento" onde os problemas citados acima são bastante críticos (Hamilton et al. 2003).

Uma das características de qualquer área do conhecimento é o dinamismo. Assim sendo, em todas as ciências, de tempos em tempos, ocorrem reformulações em seu conjunto de objetivos, em suas metodologias e teorias. Com a Etnobotânica não é diferente. $\mathrm{O}$ fato de ser uma disciplina que se tornou o alvo de muitas críticas recentes faz dela um campo 
científico no qual fervilham novas idéias e diferentes reflexões. Muitas dessas reflexões são essencialmente filosóficas, tratam de questões sobre o papel do conhecimento produzido na academia e sobre os direitos e deveres dos pesquisadores. Mas essas discussões também envolvem a necessidade de avançarmos no sentido de construir teorias da relação pessoas/plantas (ver Albuquerque 2009).

Numa época em que são debatidos tantos temas polêmicos referentes aos benefícios e aos perigos oriundos de avanços científicos, a Etnobotânica e áreas correlatas (Etnobiologia, Etnoecologia) discutem possibilidades de aproximar as pesquisas científicas das prioridades de sociedades humanas, especialmente de populações tradicionais e populações historicamente marginalizadas, incluindo a urgente necessidade de conservação e uso mais parcimonioso dos recursos naturais.

Um balanço geral da revisão realizada neste trabalho sobre os temas abordados em trabalhos etnobotânicos ao longo do desenvolvimento da disciplina permite concluir que, para a Etnobotânica, ainda encontra-se em desenvolvimento um corpo teórico, bem como um programa metodológico unificado. Existe sim um variado leque de metodologias e teorias originadas em diferentes áreas do conhecimento e que podem ser utilizadas ou não de acordo com a pergunta que se pretende responder. Este leque aumenta e se torna ainda mais variado à medida que se ampliam os tipos de problemas cujas soluções são procuradas através de abordagens etnobotânicas. No caso do Brasil, o dinamismo da disciplina foi verificado nas tendências aparentes dos trabalhos realizados no país e publicados em revistas científicas e em eventos nacionais relacionados à área. Ainda sim, somente agora, é que começam a proliferar discussões e análises críticas sobre os instrumentos de investigação utilizados na pesquisa, inclusive de técnicas quantitativas que presenciaram um forte aumento nos últimos 15 anos.

Os eventos realizados no Brasil tiveram e continuam tendo um papel fundamental nas reformulações pelas quais tem passado a Etnobotânica brasileira. Os novos direcionamentos dados à disciplina durante o século XX, especialmente a partir dos anos 1940-1950, são refletidos nos trabalhos apresentados nos CNBs e, posteriormente, nos SBEEs. A avaliação histórica destes eventos revela que a disciplina não está estagnada no Brasil, que novos temas e novas abordagens metodológicas continuam surgindo e o número de trabalhos tem aumentado.

Por fim, o contexto atual da Etnobotânica é caracterizado por uma certa indefinição sobre o destino das pesquisas dependentes de acesso ao conhecimento tradicional associado à diversidade genética. Em países megadiversos biológica e culturalmente, como é o caso do Brasil, é necessário que a legislação consiga proteger o conhecimento tradicional e o patrimônio genético do país sem impedir o desenvolvimento das pesquisas nacionais que envolvem acesso a estes elementos. O Brasil, como país signatário da Convenção sobre Diversidade Biológica (CDB), tem buscado adaptar sua legislação às determinações desta Convenção, porém os resultados desta adaptação têm prejudicado e mesmo impedido o desenvolvimento de pesquisas nacionais as quais são muitas vezes de caráter básico, simples de serem desenvolvidas e importantes na busca de soluções para preservação de recursos naturais e conhecimento tradicional. Vale ressaltar que assuntos referentes a acesso ao patrimônio genético e ao conhecimento tradicional associado têm sido amplamente abordados em fóruns brasileiros de debates envolvendo assuntos etnobotânicos. Destacam-se nestes fóruns discussões sobre as medidas deliberadas pelo "Conselho de Gestão do Patrimônio Genético/CGEN", pois tais medidas têm interferido fortemente no direcionamento dado às pesquisas na área enfocando populações tradicionais. $\mathrm{O}$ CGEN foi criado pela Medida Provisória 2186-16 num esforço de proteger a biodiversidade brasileira e conhecimento tradicional associado e assegurar os direitos de populações tradicionais no Brasil, buscando um ajuste às medidas deliberadas pela CDB.

$\mathrm{O}$ assunto é bastante polêmico, pois envolve interesses diversos e por vezes incompatíveis: a necessidade de serem desenvolvidas pesquisas nacionais básicas; os direitos e interesses de populações tradicionais e historicamente marginalizadas; e os interesses econômicos de grandes indústrias atuando na bioprospecção de recursos naturais e conhecimento associado. Este impasse parece estar longe de ser resolvido e se tornou a maior preocupação de pesquisadores etnobotânicos brasileiros já que interfere diretamente e, na maioria dos casos, de maneira negativa, nos trabalhos desenvolvidos, e que pode estar colocando um freio no crescimento e desenvolvimento da Etnobotânica no Brasil.

\section{Referências bibliográficas}

Agra, M.F.; Baracho, G.S.; Nurit, K.; Basilio, I.J.L.D. \& Coelho, V.P.M. 2007. Medicinal and poisonous diversity of the flora of "Cariri Paraibano", Brazil. Journal of Ethnopharmacology 111: 383-395.

Albuquerque, U.P. 1997. Etnobotânica de uma bebida cerimonial no nordeste do Brasil. Revista Brasileira de Farmácia 78: 86-89.

Albuquerque, U.P. 1999. Referências para o estudo da etnobotânica dos descendentes culturais do africano no Brasil. Acta Farmacéutica Bonaerense 18: 299-306.

Albuquerque, U.P. 2001. The use of medicinal plants by the cultural descendants of African people in Brazil. Acta Farmacéutica Bonaerense 20: 139-144.

Albuquerque, U.P. 2005. Introdução à Etnobotânica. $2^{\mathrm{a}}$ ed. Rio de Janeiro, Interciência. 
Albuquerque, U.P. 2009. Quantitative ethnobotany or quantification in ethnobotany? Ethnobotany Research \& Applications 7: $1-2$.

Albuquerque, U.P. \& Silva-Soares, T.A. 1996. Plantas usadas como cosméticos em Recife-Pernambuco. Revista Brasileira de Farmácia 77: 150-152.

Albuquerque, U.P. \& Andrade, L.H.C. 1998. Etnobotánica del gênero Ocimum L. (Lamiaceae) en las comunidades afrobrasileñas. Anales del Jardín Botánico de Madrid 56: 107-118.

Albuquerque, U.P. \& Andrade, L.H.C. 2002a. Conhecimento botânico tradicional e conservação em uma área de caatinga no estado de Pernambuco, Nordeste do Brasil. Acta Botanica Brasilica 16: 273-285.

Albuquerque, U.P. \& Andrade, L.H.C. 2002b. Uso de recursos vegetais da caatinga: o caso do agreste do Estado de Pernambuco (Nordeste do Brasil). Interciencia 27: 336-345

Albuquerque, U.P. \& Lucena, R.F.P. 2005. Can apparency affect the use of plants by local people in tropical forests? Interciencia 30: 506-510.

Albuquerque, U.P.; Andrade, L.H.C. \& Caballero, J. 2005a. Structure and floristics of homegardens in Northeastern Brazil. Journal of arid environments 62: 491-506.

Albuquerque, U.P.; Andrade, L.H.C. \& Silva, A.C.O. 2005b. Use of plant resources in a seasonal dry forest (Northeastern Brazil). Acta Botanica Brasilica 19: 27-38.

Albuquerque, U.P. de \& Oliveira, R.F. 2007. Is the use-impact on native caatinga species in Brazil reduced by the high species richness of medicinal plants? Journal of Ethnopharmacology 113: $156-170$.

Albuquerque, U.P.; Medeiros, P.M.; Almeida, A.L.S.; Monteiro, J.M.; Lins Neto, E.M.F.; Melo, J.G. \& Santos, J.P. 2007a. Medicinal plants of the caatinga (semi-arid) vegetation of NE Brazil: A quantitative approach. Journal of Ethnopharmacology 114: 325-354.

Albuquerque, U.P.; Monteiro, J.M.; Ramos, M.A. \& Amorim, E.L.C. 2007b. Medicinal and magic plants from a public market in northeastern Brazil. Journal of Ethnopharmacology 110: 76-91.

Albuquerque, U.P.; Lucena, R.F.P. \& Cunha, L.V.F. 2008. Métodos e técnicas na pesquisa etnobotânica. Recife, Editora Comunigraf/ NUPEEA.

Alcorn, J.B. 1995. The scope and aims of ethnobotany in a developing world. Pp. 23-39. In: R.E. Schultes \& S.V. Reis (eds.). Ethnobotany: evolution of a discipline. Cambridge, Timber Press.

Alexiades, M.N. (ed.). 1996. Selected guidelines for ethnobotanical research: a field manual. New York, The New York Botanical Garden.

Alexiades, M.N. \& Sheldon, J.W. 1996. Ethnobotanical Research: A Field Manual. New York, The New York Botanical Garden.

Allem, A.C. 2000. Ethnobotanical testimony on the ancestors of cassava (Manihot esculenta Crantz subsp. esculenta). Plant Genetic Resources Newsletter 123: 19-22.

Almeida, C.E.; Karnikowski, M.G.O.; Foleto, R. \& Baldisserotto, B. 1995. Analysis of antidiarrhoeic effect of plants used in popular medicine. Revista de Saúde Pública 29: 428-433.

Almeida, C.F.C.B.R. \& Albuquerque U.P. 2002. Uso e conservação de plantas e animais medicinais no Estado de Pernambuco (Nordeste do Brasil): um estudo de caso. Interciencia 27: 276-285.

Almeida, C.F.C.B.R.; Silva, T.C.D.E.; Amorim, E.L.C.; Maia, M.B.D. \& Albuquerque, U.P. 2005. Life strategy and chemical composition as predictors of the selection of medicinal plants from the caatinga (Northeast Brazil). Journal of arid environments 62: 127-142.

Alves, T.M.A.; Silva, A.F.; Brandão, M.; Grandi, T.S.M.; Smania, E.F.A.; Smania Júnior, A. \& Zani, C.L. 2000. Biological screening of Brazilian medicinal plants. Memórias do Instituto Oswaldo Cruz 95: 367-373.
Alves, R.R.N. \& Rosa, I.M.L. 2007. Biodiversity, traditional medicine and public health: where do they meet? Journal of Ethnobiology and Ethnomedicine 3: 14-14.

Amorozo, M.C.M. \& Gély, A.L. 1987. Uso de plantas medicinais pela população cabocla de Barcarena (PA). Pp. 409. In: Anais. $38^{\circ}$ Congresso Nacional de Botânica. São Paulo, SP.

Amorozo, M.C.M. 1997. Algumas notas adicionais sobre o emprego de plantas e outros produtos com fins terapêuticos pela população cabocla do município de Barcarena, Pa, Brasil. Boletim do Museu Paraense Emílio Goeldi, Série Botânica 13: 191-213.

Amorozo, M.C.M. 2002. Uso e diversidade de plantas medicinais em Santo Antônio de Leverger, MT, Brasil. Acta Botanica Brasilica 16: 189-203.

Anderson, A.B. 1987. A aptidão de várzeas baixas do estuário amazônico para manejo florestal. Pp. 412. In: Anais. $38^{\circ}$ Congresso Nacional de Botânica. São Paulo, SP.

Andrade, C.T.S.; Marques, J.G.W. \& Zappi, D.C. 2006. The use of medicinal cacti by locals at the semi-arid in Bahia State, Brazil. Revista Brasileira de Plantas Medicinais 8: 36-42.

Arambarri, A.M. \& Bayon, N.D. 1998. Anatomy and ethnobotany of medicinal species of monocotyledons from the Argentine pampean steppe: Poaceae. Acta Farmacéutica Bonaerense 17: 173-190.

Araújo, E.L. 2002. Production of medicinal plants for phytotherapy programs in the Public health in Brazil. Acta Horticulturae (569): 17-20.

Arjona, F.B.S.; Montezuma, R.C.M. \& Silva, I.M. 2007. Aspectos etnobotânicos e biogeografia de espécies medicinais e/ou rituais comercializadas no mercado de Madureira, RJ. Caminhos de Geografia 8: 41-50.

Azevedo, S.K.S. \& Silva, I.M. 2006. Medical and religious plants commercialized in conventional and open-air markets of Rio de Janeiro municipality Rio de Janeiro State, Brazil. Acta Botanica Brasilica 20: 185-194.

Balick, M.J. \& Cox, P.A. 1996. Plants, people and culture: the science of ethnobotany. New York, Scientific American Library.

Baracho, G.S. \& Agra, M.F. 1995. Etnomedicina da familia Malvaceae nos Cariris Velhos, Paraíba, Brasil. Revista Brasileira de Farmácia 76: 48-52.

Baraloto, E.F.; Rockwell, C. \& Walthier, F. 2007. Limitations and Applications of Parataxonomy for Community Forest Management in Southwestern Amazonia. Ethnobotany Research \& Applications 5: 77-84.

Basso, L.A.; Silva, L.H.P.; Fett Neto, A.G.; Azevedo Jr., W.F.; Moreira, I.S.; Palma, M.S.; Calixto, J.B.; Astolfi Filho, S.; Santos, R.R.; Pereira Soares, M.B. \& Santos, D.S. 2005. The use of biodiversity as source of new chemical entities against defined molecular targets for treatment of malária, tuberculosis, and T-cell mediated diseases - A Review. Memórias do Instituto Oswaldo Cruz 100: 475-506.

Bayon, N.D. \& Arambarri, A.M. 1999. Anatomy and ethnobotany of the medicinal species of the pampean province: Asclepiadaceae. Acta Farmacéutica Bonaerense 18: 23-31.

Begossi, A. 1996. Use of ecological methods in ethnobotany: Diversity indices. Economic Botany 50: 280-289.

Begossi, A.; Hanazaki, N. \& Peroni, N. 2000. Knowledge and use of biodiversity in Brazilian hot spots. Environment, Development and Sustainability 2: 177-193.

Begossi, A. 2001. Resiliência e populações neotradicionais: Os caiçaras (Mata Atlântica) e os caboclos (Amazônia, Brasil). Pp. 205-236. In: Diegues, A. C.; Moreira, A. de C. C. Espaços e recursos de uso comum. São Paulo, Nupaub, USP.

Begossi, A.; Hanazaki, N. \& Tamashiro, J.Y. 2002. Medicinal plants in the Atlantic Forest (Brazil): Knowledge, use, and conservation. Human ecology 30: 281-299.

Berkes, F.; Folke, C. \& Gadgil, M. 1995. Traditional ecological knowledge, biodiversity, resilience and sustainability. Pp. 281-300. In: C.S. Perrings; K.G. Mäler; C. Folke; C.S. Holling \& B.O. Jansson (eds.). Biodiversity conservation. Problems and policies. Dordrecht, Kluwer Academic Press. 
Berlin, B.; Breedlove, D.E. \& Raven, P.H. 1966. Folk taxonomies and biological classification. Science 154: 273-275.

Berlin, B; Breedlove, D.E. \& Raven, P.H. 1968. Covert Categories and Folk Taxonomies. American Anthropologist 70: 290-299.

Berlin, B.; Breedlove, D.E. \& Raven, P.H. 1973. General principles of classification and nomenclature in folk biology. American Anthropologist 75: 214-242.

Borba, A.M. \& Macedo, M. 2006. Medicinal plants used for oral health in the Santa Cruz neighborhood, Chapada dos Guimarães, Mato Grosso State, Brazil. Acta Botanica Brasilica 20: 771-782.

Bortolotto, I.M. \& Guarim Neto, G. 2005. O uso do camalote, Eichhornia crassipes (Mart.) Solms, Pontederiaceae, para confecção de artesanato no Distrito de Albuquerque, Corumbá, MS, Brasil. Acta Botanica Brasilica 19: 331-337.

Botrel, R.T.; Rodrigues, L.A.; Gomes, L.J.; Carvalho, D.A. \& Fontes, M.A.L. 2006. Use of native vegetation by the local population in Ingaí municipacity, Minas Gerais State, Brazil. Acta Botanica Brasilica 20: 143-156.

Brandão, M.G.L.; Grandi, T.S.M.; Rocha, E.M.M.; Sawyer, D.R. \& Krettli, A.U. 1992. Survey of medicinal plants used as antimalarials in the Amazon. Journal of Ethnopharmacology 36: $175-182$.

Bueno, N.R.; Castilho, R.O.; Costa, R.B.; Pott, A.; Pott, V.J.; Scheidt, G.N. \& Batista, M.S. 2005. Medicinal plants used by the Kaiowá and Guarani indigenous populations in the Caarapó Reserve, Mato Grosso do Sul, Brazil. Acta Botanica Brasilica 19: 39-44.

Campos, M.T. \& Ehringhaus, C. 2003. Plant virtues are in the eyes of the beholders: A comparison of known palm uses among indigenous and folk communities of Southwestern Amazonia. Economic Botany 57: 324-344.

Castellucci, S.; Lima, M.I.S.; Nordi, N. \& Marques, J.G.W. 2000. Plantas medicinais relatadas pela comunidade residente na Estação Ecológica de Jataí, município de Luís Antônio/SP: uma abordagem etnobotânica. Revista Brasileira de Plantas Medicinais 3: 51-60.

Castro, H.G. \& Ferreira, F.A. 2001. A dialética do conhecimento no uso das plantas medicinais. Revista Brasileira de Plantas Medicinais 3: 19-21.

Cataluña, P. \& Rates, S.M.K. 1999. The traditional use of the latex from Euphorbia tirucalli Linnaeus (Euphorbiaceae) in the treatment of cancer in South Brazil. Acta Horticulturae 501: 289-295.

Chaves, S.A.D.M. \& Reinhard, K.J. 2006. Critical analysis of coprolite evidence of medicinal plant use, Piaú, Brazil. Palaeogeography, Palaeoclimatology, Palaeoecology 237: 110-118.

Clément, D. 1998. The historical foundations of ethnobiology (18601899). Journal of Ethnobiology 18: 161-187.

Colares, M.N.; Bayon, N.D.; Stenglein, S.A. \& Arambarri, A.M. 1999. Anatomy and ethnobotany of medicinal species of the pampean province: Solanaceae (excluded Grabowskia and Solanum). Acta Farmacéutica Bonaerense 18: 171-182.

Conklin, H.C. 1955. Hanunoo color categories. Southwestern Journal of Anthropology 11: 339-344.

Conklin, H.C. 1957. Hanunoo agriculture: a report on an integral system of shifting cultivation. FAO Forestry Development Paper $\mathbf{n}^{\circ}$ 12. Rome, FAO.

Conklin, H.C. 1962. Lexicographical Treatment of Folk Taxonomies. Reprinted from Actional Journal of american Linguistics 4: 119-141.

Costa, L.C.D.B.; Rocha, E.A.; Silva, L.A.M.; Jardim, J.G.; Silva, D.D.C.; Gaião, L.D.O. \& Moreira, R.D.C.T. 2006. Preliminar survey of plants with economic interest in the neighborhood community of the "Boa Esperança" city park, Ilhéus, Bahia, Brazil. Acta Farmacéutica Bonaerense 25: 184-191.

Costa Neto, E.M. \& Oliveira, M.V.M. 2000. The use of medicinal plants in the county of Tanquinho, State of Bahia, Northeastern Brazil. Revista Brasileira de Plantas Medicinais 2: 1-8.
Cruz, A.V.M. \& Kaplan, M.A.C. 2004. Uso medicinal de espécies das famílias Myrtaceae e Melastomataceae no Brasil. Floresta e Ambiente 11: 47-52

Cruz, M.C.S.; Santos, P.O.; Barbosa, A.M.; Melo, D.L.F.M.; Alviano, C.S.; Antoniolli, A.R.; Alviano, D.S. \& Trindade, R.C. 2007. Antifungal activity of Brazilian medicinal plants involved in popular treatment of mycoses. Journal of Ethnopharmacology 111: 409-412.

Cunha, M.C. 1999. Populações tradicionais e a Convenção da Diversidade Biológica. Estudos Avançados 13: 117-163.

Cunha, L.V.F.C. \& Albuquerque, U.P. 2006. Quantitative ethnobotany in an Atlantic Forest fragment of Northeastern Brazil Implications to conservation. Environmental Monitoring and Assessment 114: 1-25.

Cunningham, A. 2000. Applied ethnobotany: people, wild plant use and conservation. London, Earthscan.

Davis, E.W. 1995. Ethnobotany: an old practice, a new discipline. Pp. 40-51. In: R.E. Schultes \& S.V. Reis (eds). 1995. Ethnobotny: evolution of a discipline. Cambridge, Timber Press.

Dickel, M.L.; Rates, S.M.K. \& Ritter, M.R. 2007. Plants popularly used for loosing weight purposes in Porto Alegre, South Brazil. Journal of Ethnopharmacology 109: 60-71.

Di Stasi, L.C. 2005. An integrated approach to identification and conservation of medicinal plants in the tropical forest - a Brazilian experience. Plant Genetic Resources: Characterization and Utilization 3: 199-205.

Di Stasi, L.C.; Hiruma, C.A.; Guimarães, E.M. \& Santos, C.M. 1994. Medicinal plants popularly used in Brazilian Amazon. Fitoterapia 65: 529-540.

Di Stasi, L.C.; Oliveira, G.P.; Carvalhaes, M.A.; Queiroz-Junior, M.; Tien, O.S.; Kakinami, S.H. \& Reis, M.S. 2002. Medicinal plants popularly used in the Brazilian Tropical Atlantic Forest. Fitoterapia 73: 69-91.

Dorigoni, P.A.; Ghedini, P.C.; Froìes, L.F.; Baptista, K.C.; Ethur, A.B.M.; Baldisserotto, B.; Burger, M.E. \& Zaìchia, R.A. 2001. Levantamento de dados sobre plantas medicinais de uso popular no municiìpio de SaPo JoaPo do Polesine, RS, Brasil. I - Relação entre enfermidades e espeìcies utilizadas. Revista Brasileira de Plantas Medicinais 4: 69-79.

Elisabetsky, E. \& Castilhos, Z.C. 1990. Plants used as analgesics by Amazonian caboclos as a basis for selecting plants for investigation. International Journal of Crude Drug Research 28: 309-320.

Elisabetsky, E. \& Wannmacher, L. 1993. The status of ethnopharmacology in Brazil. Journal of Ethnopharmacology 38: $137-143$.

Elisabetsky, E. 2003. Direitos de propriedade intelectual e distribuição eqüitativa de benefícios no contexto de inovação tecnológica. Pp. 170-174. In: Anais. I Simpósio de Etnobiologia e Etnoecologia da Região Sul: Aspectos humanos da biodiversidade. Florianópolis, SC.

Ferraz, J.S.F.; Albuquerque, U.P. \& Meunier, I.M.J. 2006. Use-value and phytosociology of woody plants on the banks of the Riacho do Navio stream, Floresta, Pernambuco State, Brazil. Acta Botanica Brasilica 20: 125-134.

Fewkes, J.W. 1896. A contribution to ethnobotany. American Anthropologist 9: 14-21.

Figueiredo, G.M.; Leitão Filho, H.F. \& Begossi, A. 1993. Ethnobotany of Atlantic forest coastal communities: Diversity of plant uses in Gamboa (Itacuruçá Island, Brazil). Human Ecology 21: 419-430.

Figueiredo, G.M.; Leitão Filho, H.F. \& Begossi, A. 1997. Ethnobotany of Atlantic Forest coastal communities. II. Diversity of plant uses at Sepetiba Bay (SE Brazil). Human Ecology 25: 353-360.

Florentino, A.T.N.: Araújo, E.D.L. \& Albuquerque, U.P. 2007. Contribution of homegardens to the conservation of caatinga plants, Municipality of Caruaru, Pernambuco State, Brazil. Acta Botanica Brasilica 21: 37-47.

Folke, C. \& Berkes, F. 1998. Understanding dynamics of ecossistem-institution linkages for building resilience. Stockholm, Beijer Discussion Paper Series. 112. 
Fonseca-Kruel, V.S. \& Peixoto, A.L. 2004. Etnobotânica na Reserva Extrativista Marinha de Arraial do Cabo, Rio de Janeiro, Brazil. Acta Botanica Brasilica 18: 177-190.

Fonseca-Kruel, V.S.; Silva, I.M. \& Pinheiro, C.U.B. 2005. O ensino acadêmico da Etnobotânica no Brasil. Rodriguésia 56: 97-106.

Ford, R.I. 1978. Ethnobotany: historical diversity and synthesis. In: R.I. Ford; M. Hodge \& W.L. Merril (eds.). The nature and status of ethnobotany. Annals of Arnold Arboretum. Michigan: Museum of Anthropology, University of Michigan. Anthropological Papers 67: 33-49.

França, F.; Lago, E.L. \& Marsden, P.D. 1996. Plants used in the treatment of leishmanial ulcers due to Leishmania (Vannia) braziliensis in an endemic area of Bahia, Brazil. Revista da Sociedade Brasileira de Medicina Tropical 29: 229-232.

Franco, E.A.P. \& Barros, R.F.M. 2006. Use and diversity of medicinal plants at the "Quilombo Olho D'água dos Pires”, Esperantina, Piauí State, Brazil. Revista Brasileira de Plantas Medicinais 8: 78-88.

Freire, S.E.; Arambarri, A.M.; Mandrille, E.L. \& Degenhardt, S. 1997. Anatomy and ethnobotany of the medicinal species of monocotyledons of the pampean steppe. Key of species. Acta Farmacéutica Bonaerense 16: 69-82.

Fuck, S.B.; Athanazio, J.C.; Lima, C.B. \& Ming, L.C. 2005. Plantas medicinais utilizadas na medicina popular por moradores da área urbana de Bandeirantes, Paraná, Brasil. Semina: Ciências Agrárias Londrina 26: 291-296.

Garlet, T.M.B. \& Irgang, B.E. 2001. Plantas medicinais utilizadas na medicina popular por mulheres trabalhadoras rurais de Cruz Alta, Rio Grande do Sul, Brasil. Revista Brasileira de Plantas Medicinais 4: 9-18.

Gazzaneo, L.R.S.; Lucena, R.F.P. \& Albuquerque, U.P. 2005. Knowledge and use of medicinal plants by local specialists in a region of Atlantic Forest in the state of Pernambuco (Northeastern Brazil). Journal Ethnobiology and Ethnomedicine 1(9).

Gély, A.L.; Anderson, A.B. \& Jardim, M.A.G. 1987. Manejo florestal por populações ribeirinhas no estuário amazônico. Pp. 410. In: Anais. $38^{\circ}$ Congresso Nacional de Botânica. São Paulo, SP.

Ghedini, P.C.; Dorigoni, P.A.; Almeida, C.E.; Ethur, A.B.M.; Lopes, A.M.V. \& Zachia, R.A. 2002. Levantamento de dados sobre plantas medicinais de uso popular no município de São João do Polesine, RS. II - Emprego de preparações caseiras de uso medicinal. Revista Brasileira de Plantas Medicinais 5: 46-55.

Gilbert, B.; Ferreira, J.L.P.; Almeida, M.B.S.; Carvalho, E.S.; Cascon, V. \& Rocha, L.M. 1997. The official use of medicinal plants in public health. Ciência e Cultura 49: 339-344.

Giorgetti, M.; Negri, G. \& Rodrigues, E. 2007. Brazilian plants with possible action on the central nervous system - A study of historical sources from the $16^{\text {th }}$ to $19^{\text {th }}$ century. Journal of Ethnopharmacology 109: 338-347.

Gottlieb, O.R. \& Borin, M.R.M.B. 1995. Chemosystematic clues for the choice of medicinal and food plants in Amazônia. Biotropica 27: 401-406.

Gottlieb, O.R. \& Borin, M.R.M.B. 2002. Shamanism or science? Anais da Academia Brasileira de Ciências 74: 135-144.

Gottlieb, O.R.; Borin, M.R.M.B.; Pagotto, C.L.A.C. \& Zocher, D.H.T. 1999. Leading motives of recent studies on Brazilian biodiversity. Acta Horticulturae 500: 169-175.

Gottlieb, O.R.; Borin, M.R.M.B. \& Brito, N.R.S. 2001. Quantitative chemobiology. Pure and Applied Chemistry 73: 583-588.

Gottlieb, O.R.; Borin, M.R.M.B. \& Brito, N.R.S. 2002. Integration of ethnobotany and phytochemistry dream or reality? Phytochemistry 60: 145-152.

Grob, C.S.; McKenna, D.J.; Callaway, J.C.; Brito, G.S.; Neves, E.S.; Oberlaender, G.; Saide, O.L.; Labigalini, E.; Tacla, C.; Miranda, C.T.; Strassman, R.J. \& Boone, K.B. 1996. Human psychopharmacology of hoasca, a plant hallucinogen used in ritual context in Brazil. Journal of Nervous and Mental Disease 184: 86-94.

Guarim Neto, G. 1997. A importância da flora amazônica para uso medicinal. Horticultura Brasileira 15(Suppl.): 159-161.

Guarim Neto, G. \& Morais, R.G. 2003. Recursos medicinais de espécies do Cerrado de Mato Grosso: um estudo bibliográfico. Acta Botanica Brasilica 17: 561-584.

Guarim Neto, G.; Santana, S.R. \& Silva, J.V.B. 2000. Notas etnobotânicas de espécies de Sapindaceae Jussieu. Acta Botanica Brasilica 14: 327-334.

Guerra, A.M.N.M.; Cunha Neto, J.R.; Marques, J.V.A.D.; Pessoa, M.F. \& Maracajá, P.B. 2007 . Plantas medicinais e hortaliças usadas para cura de doenças em residências da cidade de Mossoró RN. Revista Verde de Agroecologia e Desenvolvimento Sustentável 2: 70-77.

Gurgel, L.A.; Sidrim, J.J.C.; Martins, D.T.; Cechinel Filho, V. \& Rao, V.S. 2005. In vitro antifungal activity of dragon's blood from Croton urucurana against dermatophytes. Journal of Ethnopharmacology 97: 409-412.

Hamilton, A.C.; Shengji, P.; Kessy, J.; Khan, A.A.; Lagos-Witte, S. \& Shinwari, Z.K. 2003. The purposes and teaching of Applied Ethnobotany. Godalming, People and Plants working paper. 11. WWF.

Hanazaki, N.; Leitão Filho, H.F. \& Begossi, A. 1996. The use of resources of the Brazilian Atlantic forest: The case of Ponta do Almada (Ubatuba, Brasil). Interciencia 21: 268-276.

Hanazaki, N.; Tamashiro, J.Y.; Leitão-Filho, H.F. \& Begossi, A. 2000. Diversity of plant uses in two Caiçara communities from the Atlantic Forest coast, Brazil. Biodiversity and Conservation 9: 597-615.

Hanazaki, N.; Souza, V.C. \& Rodrigues, R.R. 2006. Ethnobotany of rural people from the boundaries of Carlos Botelho State Park, São Paulo State, Brazil. Acta Botanica Brasilica 20: 899-909.

Harshberger, J.W. 1896. Purposes of ethnobotany. Botanical Gazette 21: 146-154.

Haverroth, M. 1997. Etnobotânica: uma revisão teórica. Antropologia em primeira mão 20: 1-56.

Holetz, F.B.; Pessini, G.L.; Sanches, N.R.; Cortez, D.A.G.; Nakamura, C.V. \& Dias Filho, B.P. 2002. Screening of some plants used in the Brazilian folk medicine for the treatment of infectious diseases. Memórias do Instituto Oswaldo Cruz 97: 1027-1031

Jacomassi, E. \& Piedade, L.H. 1994. A importância das plantas com finalidades terapêuticas e suas aplicações na cidade de GoierêPR. Revista UNIMAR 16: 335-353.

Jardim, M.A.G. \& Anderson, A.B. 1987. Manejo de açaizeiro (Euterpe oleracea) na várzea do estuário amazônico: resultados preliminares. Pp. 411. In: Anais. $38^{\circ}$ Congresso Nacional de Botânica. São Paulo, SP.

Jardim, M.A.G. \& Cunha, A.C.C. 1998. Uses of palm in the wet lands communities of the Amazon estuary. Boletim do Museu Paraense Emilio Goeldi Série Botânica 14: 69-77.

Knoss, W. \& Falkenberg, M. 2000. Phytotherapy in Brazil. Zeitschrift fur Phytotherapie 21: 328-338.

Leal, M.B. \& Elisabetsky, E. 1996. Absence of alkaloids in Psychotria carthagenensis Jacq. (Rubiaceae). Journal of Ethnopharmacology 54: 37-40.

Leão, R.; Ferreira, M.R.C. \& Jardim, M.A.G. 2007. Levantamento de plantas de uso terapêutico no município de Santa Bárbara do Pará, Estado do Pará, Brasil. Revista Brasileira de Farmácia 88: $21-25$.

Lucena, R.F.P.; Albuquerque, U.P.; Monteiro, J.M.; Almeida, C.D.F.B.R.; Florentino, A.T.N. \& Ferraz, J.S.F. 2007. Useful plants of the semi-arid northeastern region of Brazil - A look at their conservation and sustainable use. Environmental Monitoring and Assessment 125: 281-290.

Maioli-Azevedo, V. \& Fonseca-Kruel, V.S. 2007. Medicinal and ritual plants sold in street markets of Rio de Janeiro, RJ, Brazil: A case study in the North and South zones. Acta Botanica Brasilica 21: 263-275.

Mans, D.R.A.; Rocha, A.B. \& Schwartsmann, G. 2000. Anti-Cancer Drug Discovery and Development in Brazil: Targeted Plant 
Collection as a Rational Strategy to Acquire Candidate AntiCancer Compounds. The Oncologist 5: 185-198.

Marçal, A.C.; Perotti, L.; Defani, M.A. \& Viscovini, R.C. 2003. Ethnobotanical survey of the medicinal plants used by the population of Goioerê-PR. Arquivos de Ciências da Saúde da UNIPAR 7: 21-26.

Marimon, B.S. \& Felfili, J.M. 2001. Ethnobotanical comparison of "Pau Brasil" (Brosimum rubescens Taub.) forests in a Xavante Indian and a non-Xavante community in Eastern Mato Grosso State, Brazil. Economic botany 55: 555-569.

Marinho, M.L.; Alves, M.S.; Rodrigues, M.L.C.; Rotondano, T.E.F.; Vidal, I.F.; Silva, W.W. \& Athayde, A.C.R. 2007. The use of medicinal plants in veterinary medicine: Rescuing the popular knowledge. Revista Brasileira de Plantas Medicinais 9: 64-69.

Marodin, S.M. \& Baptista, L.R.M. 2001a. O uso de plantas com fins medicinais no município de Dom Pedro de Alcântara, Rio Grande do Sul, Brasil. Revista Brasileira de Plantas Medicinais 4: 57-68

Marodin, S.M. \& Baptista, L.R.M. 2001b. Plantas utilizadas como medicinais no município de Dom Pedro de Alcântara, Rio Grande do Sul, Brasil. 1. Origem e aspectos ecológicos. Iheringia Série Botânica 56: 131-146.

Martin, G.J. 1995. Ethnobotany. London, Chapman \& Hall.

Martínez-Alfaro, M. 1994. Estado actual de las investigaciones etnobotánicas en México. Boletín de la Sociedad Botánica de México 55: 67-74.

Martins, D.T.O. \& Gonçalves, M.I.A. 1998. Plantas medicinais usadas pela população do município de Santo Antonio de Leverger, Mato Grosso, Brasil. Revista Brasileira de Farmácia 79: 56-61.

Martins, E.R. \& Oliveira, L.O. 2004. Conservação da poaia (Psychotria ipecacuanha Stand1.): I - Estratégias de localização de populações e etnobotânica. Revista Brasileira de Plantas Medicinais 7: 6-10.

Martins, L.G.S.; Senna-Valle, L. \& Pereira, N.A. 2005. Princípios ativos e atividades farmacológicas de 8 plantas popularmente conhecidas por nome de medicamentos comerciais. Revista Brasileira de Plantas Medicinais 7: 73-76.

Medeiros, M.F.T.; Fonseca, V.S. \& Andreata, R.H.P. 2004. Plantas medicinais e seus usos pelos sitiantes da Reserva Rio das Pedras, Mangaratiba, RJ, Brasil. Acta Botanica Brasilica 18: 391-399.

Medeiros, M.F.T.; Senna-Valle, L. \& Andreata, R.H.P. 2005. Flora medicinal dos sitiantes da reserva particular do patrimônio natural Rio das Pedras, Mangaratiba, Rio de Janeiro, Brasil: Taxonomia e Aspectos Etnobotânicos. Publicações Avulsas do Museu Nacional (Rio de Janeiro) (103): 3-24.

Melo Júnior, E.J.M.; Raposo, M.J.; Lisboa Neto, J.A.; Diniz, M.F.A.; Marcelino Júnior, C.A.C. \& Sant'Ana, A.E.G. 2002. Medicinal plants in the healing of dry socket in rats: microbiological and microscopic analysis. Phytomedicine 9: 109-116.

Menezes, F.S.; Falcão, D.Q.; Mendonça Filho, R.F.W.; Silveira, C.S.; Renno, M.N.; Rodrigues, V.P.; Minto, A.B.M.; Moreira, D.L.; Matheus, M.E.; Fernandes, P.D. \& Kaplan, M.A.C. 2005. Chemical and pharmacological survey on Brazilian medicinal plants using ethnopharmacological information as a tool. Acta Horticulturae 675: 89-95.

Metzger, D. \& Williams, G.E. 1966: Some procedures and results in the study of native categories: Tzeltal firewood. American Anthropologist 68: 389-407

Meurer-Grimes, B.; Berkov, A. \& Beck, H. 1998. Theobromine, theophylline, and caffeine in 42 samples and products of guarana (Paullinia cupana, Sapindaceae). Economic Botany 52: 293-301.

Minnis, P.E. 2000. Introduction. Pp.3-10. In: P.E. Minnis (ed.). Ethnobotany: a reader. Norman, University of Oklahoma Press.

Miranda, T.M.; Amorozo, M.C.D.; Govone, J.S. \& Miranda, D.M. 2007. The influence of visual stimuli in ethnobotanical data collection using the listing task method. Field Methods 19:
76-86.

Monteiro, J.M.; Albuquerque, U.P.D.; Lins Neto, E.M.F.; Araújo, E.L.D. \& Amorim, E.L.C.D. 2006. Use patterns and knowledge of medicinal species among two rural communities in Brazil's semi-arid northeastern region. Journal of Ethnopharmacology 105: 173-186.

Moreira, R.C.T.; Costa, L.C.D.B.; Costa, R.C.S. \& Rocha, E.A. 2002. Abordagem etnobotânica acerca do uso de plantas medicinais na Vila Cachoeira, Ilhe’us, Bahia, Brasil. Acta Farmacéutica Bonaerense 21: 205-211.

Mukherjee, P.K. 2005. International Conference on Natural Health Products: "Promotion and Development of Botanicals With International Coordination: Exploring Quality, Safety, Efficacy, and Regulations". Drug Information Journal 39: 457-463.

Napolitano, D.R.; Mineo, J.R.; Souza, M.A.; Paula, J.E.; Espindola, L.S. \& Espindola, F.S. 2005. Down-modulation of nitric oxide production in murine macrophages treated with crude plant extracts from the Brazilian Cerrado. Journal of Ethnopharmacology 99: 37-41.

Nappo, A.E.; Fiedler, N.C.; Silva, J.C. \& Silva, G.F. 2003. Avaliação da utilização de recursos florestais no extremo nordeste do estado de Goiás. Brasil Florestal 21: 15-22.

Negrelle, R.R.B. \& Fornazzari, K.R.C. 2007. Ethnobotanical study in two rural communities (Limeira and RiberiaPo Grande) in Guaratuba (Paranaì, Brazil). Revista Brasileira de Plantas Medicinais 9: $36-54$

Negrelle, R.R.B.; Tomazzoni, M.I.; Ceccon, M.F. \& Valente, T.P. 2007. Ethnobotanical study near by the Family Health Care Unit of Nossa Senhora dos Navegantes: Subsidies for the establishment of the program of phytotherapies in the Public Health System of the municipality Cascavel, Parana State, Brazil. Revista Brasileira de Plantas Medicinais 9: 6-22.

Negri, G. 2005. Diabetes melito: plantas e princípios ativos naturais hipoglicemiantes. Revista Brasileira de Ciências Farmacêuticas 41: 121-142.

NSF Biocomplexity Workshop Report. 2003. Intellectual Imperatives in Ethnobiology. Misoouri Botanical Garden.

Nunes, D.S. \& Imamura, P.M. 1996. A program for organizing field research data and bibliography on medicinal plants. Ciência e Cultura São Paulo 48: 232-237.

Oliveira, F.Q.; Junqueira, R.G.; Stehmann, J.R. \& Brandão, M.G.L. 2003. Potencial das plantas medicinais como fonte de novos antimalaìricos: Espeìcies indicadas na bibliografia etnomeìdica Brasileira. Revista Brasileira de Plantas Medicinais 5: 23-31.

Oliveira, D.R.; Leitão, G.G.; Santos, S.S.; Bizzo, H.R.; Lopes, D.; Alviano, C.S.; Alviano, D.S. \& Leitão, S.G. 2006. Ethnopharmacological study of two Lippia species from Oriximiná, Brazil. Journal of Ethnopharmacology 108: 103-108.

Oliveira, R.L.C.; Lins Neto, E.M.F.; Araújo, E.L. \& Albuquerque, U.P. 2007. Conservation priorities and population structure of woody medicinal plants in an area of caatinga vegetation (Pernambuco State, NE Brazil). Environmental monitoring and assessment 132: 189-206.

Parente, C.E.T. \& Rosa, M.M.T. 2001. Plantas comercializadas como medicinais no Município de Barra do Piraí, RJ. Rodriguésia 52: 47-59.

Pasa, M.C.; Soares, J.J. \& Guarim Neto, G. 2005. Estudo etnobotânico na comunidade de Conceição-Açu (alto da bacia do rio Aricá Açu, MT, Brasil). Acta Botanica Brasilica 19: 195-207.

Pereira, C.O.; Lima, E.O.; Oliveira, R.A.G.; Toledo, M.S.; Azevedo, A.K.A.; Guerra, M.F. \& Pereira, R.C. 2005. Abordagem etnobotânica de plantas medicinais utilizadas em dermatologia na cidade de João Pessoa-Paraíba, Brasil. Revista Brasileira de Plantas Medicinais 7: 9-17.

Peres, V.; Nagem, T.J.; Oliveira, F.F. \& Oliveira, T.T. 2002. The chemosystematic significance of xanthones in Gentianaceae. Current Topics in Phytochemistry 5: 23-38.

Peroni, N. \& Martins, P.S. 2000. Influência da dinâmica agrícola 
itinerante na geração de diversidade de etnovariedades cultivadas vegetativamente. Interciencia 25: 22-29.

Peroni, N.; Kageyama, P.Y. \& Begossi, A. 2007. Molecular differentiation, diversity, and folk classification of "sweet" and "bitter" cassava (Manihot esculenta) in Caiçara and Caboclo management systems (Brazil). Genetic Resources and Crop Evolution 54: 1333-1349.

Phillips, O. \& Gentry, A.H. 1993a. The useful plants of Tambopata, Peru: I. Statistical hypotheses tests with a new quantitative technique. Economic Botany 47: 15-32.

Phillips, O. \& Gentry, A.H. 1993b. The useful plants of Tambopata, Peru: II. Aditional hypothesis testing in quantitative ethnobotany. Economic Botany 47: 33-43.

Pilla, M.A.C.; Amorozo, M.C.D.M. \& Furlan, A. 2006. Acquisition and use of medicinal plants in Martim Francisco district, Mogi Mirim Municipality, São Paulo State, Brazil. Acta Botanica Brasilica 20: 789-802.

Pimbert, M.P. \& Pretty, J.N. 2000. Parques, comunidades e profissionais: incluindo 'participação' no manejo de áreas protegidas. Pp. 183224. In: A.C. Diegues (org.). Etnoconservação: novos rumos para a proteção da natureza nos trópicos. São Paulo, Hucitec.

Pimentel, E.C. 2006. Integral health and medicinal plants: phytotherapy's understand in ampler concepts. Revista de Ciências Agroveterinárias 5: 49-52.

Pinheiro, C.U.B. 1997. Jaborandi (Pilocarpus sp., Rutaceae): a wild species and its rapid transformation into a crop. Economic Botany 51: 49-58

Pinto, E.D.P.P.; Amorozo, M.C.D.M. \& Furlan, A. 2006. Folk knowledge about medicinal plants within rural communities in Atlantic Forest, Itacaré, Bahia State, Brazil. Acta Botanica Brasilica 20: 751-762.

Prance, G.T. 1983. Pesquisas botânicas e a conservação da floresta amazônica. Pp.63-71. In: Anais. 34 ${ }^{\circ}$ Congresso Nacional de Botânica. Volume I - Simpósios. Porto Alegre, RS.

Prance, G.T. 1991. What is Ethnobotany today. Journal of Ethnopharmacology 32: 209-216.

Rezende, E.A. \& Ribeiro, M.T.F. 2005. Conhecimento tradicional, plantas medicinais e propriedade intelectual: biopirataria ou bioprospecção? Revista Brasileira de Plantas Medicinais 7: $37-44$.

Ribeiro, D. 1987. Suma etnológica brasileira. Edição atualizada do "Handbook of south american indian". Petrópolis, Vozes.

Rocha, E.A. \& Agra, M.F. 1996. The ethnomedicinal evaluation of the Lamiaceae family of the Cariris Velhos, Paraíba, Brazil. Revista Brasileira de Farmácia 77: 19-24.

Rocha, A.E.S. \& Silva, M.F.F. 2005. Aspectos fitossociológicos, florísticos e etnobotânicos das palmeiras (Arecaceae) de floresta secundária no município de Bragança, PA, Brasil. Acta Botanica Brasilica 9: 657-667.

Rodrigues, E. 1998. Etnofarmacologia no Parque Nacional do Jaú, AM. Revista Brasileira de Plantas Medicinais 1: 1-14.

Rodrigues, E. 2006. Plants and animals utilized as medicines in the Jaú National Park (JNP), Brazilian Amazon. Phytotherapy Research 20: 378-391.

Rodrigues, E. 2007. Plants of restricted use indicated by three cultures in Brazil (Caboclo-river dweller, Indian and Quilombola). Journal of Ethnopharmacology 111: 295-302.

Rodrigues, E. \& Carlini, E.A. 2005. Ritual use of plants with possible action on the central nervous system by the Kraho Indians, Brazil. Phytotherapy Research 19: 129-135.

Rodrigues, E. \& Carlini, E.A. 2006. A comparison of plants utilized in ritual healing by two Brazilian cultures: Quilombolas and Kraho Indians. Journal of Psychoactive Drugs 38: 285-295.

Rodrigues, A.C.C. \& Guedes, M.L.S. 2006. Utilização de plantas medicinais no Povoado Sapucaia, Cruz das Almas-Bahia. Revista Brasileira de Plantas Medicinais 8: 1-7.

Rodrigues, R.F.O.; Oliveira, F. \& Fonseca, A.M. 2002. The leaves of Palma Christi-Ricinus communis L. Euphorbiaceae Jussieu - A review. Lecta 20: 183-194.

Rossato, S.C.; Leitão Filho, H.F. \& Begossi, A. 1999. Ethnobotany of Caiçaras of the Atlantic Forest coast (Brazil). Economic Botany 53: 387-395.

Sambatti, J.B.M.; Martins, P.S. \& Ando, A. 2001. Folk taxonomy and evolutionary dynamics of cassava: a case study in Ubatuba, Brazil. Economic Botany 55: 93-105.

Sangalli, A.; Vieira, M.C. \& Heredia, N.A.Z. 2002. Surveying and characterization of native plants with medicinal properties at forest and Cerrado fragments in Dourados-MS in a ethnobotany view. Acta Horticulturae 569: 173-184.

Santos, F.S.D. 2000. Tradições populares de uso de plantas medicinais na Amazônia. História, Ciências, Saúde-Manguinhos 6(Suppl.0): 919-939.

Santos, M.A.C. \& Elisabetsky, E. 1999. Ethnopharmacology as a tool for the selection of medicinal plants for screening antitumour activity. Revista Brasileira de Plantas Medicinais 2: 7-17.

Santos, M.G. \& Sylvestre, L.S. 2000. Pteridófitas comercializadas por erveiros de Niterói e do Rio de Janeiro, RJ, Brasil: uma abordagem etnobotânica. Leandra 15: 79-90.

Santos, M.G.; Dias, A.G.P. \& Martins, M.M. 1995. Conhecimento e uso da medicina alternativa entre alunos e professores de primeiro grau. Revista de Saúde Pública 29: 221-227.

Schardong, R.M.F. \& Cervi, A.C. 2000. Estudos etnobotânicos das plantas de uso medicinal e místico na comunidade de São Benedito, Bairro São Francisco, Campo Grande, MS, Brasil. Acta Biológica Paranaense 29: 187-217.

Schmidt, I.B.; Figueiredo, I.B. \& Scariot, A. 2007. Ethnobotany and effects of harvesting on the population ecology of Syngonanthus nitens (Bong.) Ruhland (Eriocaulaceae), a NTFP from Jalapão region, central Brazil. Economic Botany 61: 73-85.

Schultes, R.E. \& Reis, S.V. (eds.). 1995. Ethnobotny: evolution of a discipline. Cambridge, Timber Press.

Second, G.; Allem, A.C.; Mendes, R.A.; Carvalho, L.J.C.B.; Emperaire, L.; Ingram, C. \& Colombo, C. 1997. Molecular marker (AFLP) based Manihot and cassava numerical taxonomy and genetic structure analysis in progress: implications for their dynamic conservation and genetic mapping. African Journal of Root and Tuber Crops 2: 140-147.

Seixas, C.S. 2005. Abordagens e técnicas de pesquisa participativa em gestão de recursos naturais. Pp. 73-105. In: P.F. Vieira; F. Berkes \& C.S. Seixas. Gestão integrada e participativa de recursos naturais: conceitos, métodos e experiências. Florianópolis, Secco/APED.

Shanley, P. \& Luz, L. 2003. The impacts of forest degradation on medicinal plant use and implications for health care in eastern Amazônia. Bioscience 53: 573-584.

Shanley, P. \& Rosa, N.A. 2004. Eroding knowledge: An ethnobotanical inventory in eastern Amazonia's logging frontier. Economic Botany 58: 135-160.

Shanley, P. \& Rosa, N.A. 2005. Conhecimento em erosão: um inventário etnobotânico na fronteira de exploração da Amazônia Oriental. Boletim do Museu Paraense Emílio Goeldi, Série Ciências Naturais 1: 147-171.

Silva, A.C.O. \& Albuquerque, U.P. 2005. Woody medicinal plants of the caatinga in the state of Pernambuco (Northeast Brazil). Acta Botanica Brasilica 19: 17-26.

Silva, V.A. \& Andrade, L.H.C. 1998. Etnobotânica Xucuru: Plantas medicinais. Revista Brasileira de Farmácia 79: 33-36.

Silva, V.A. \& Andrade, L.H.C. 2004. O significado cultural das espécies botânicas entre indígenas de Pernambuco: o caso Xucuru. Biotemas 17: 79-94.

Silva, A.J.R. \& Andrade, L.H.C. 2005. Etnobotânica nordestina: estudo comparativo da relação entre comunidades e vegetação na Zona do Litoral - Mata do Estado de Pernambuco, Brasil. Acta Botanica Brasilica 19: 45-60.

Silva, A.J.R. \& Andrade, L.H.C. 2006. Cultural significance of plants in communities located in the coastal forest zone of the State of Pernambuco, Brazil. Human Ecology 34: 447-465.

Silva, G.L.C.; Gaertner, P.; Marson, P.G.; Schwarz, E.D.A. \& Santos, 
C.A.D.M. 2004. An ethno-pharmacobotanical survey in Salto Caxias Hydroelectric power plant in Parana' State, Brazil, before the flooding. Acta Farmacéutica Bonaerense 23: $148-153$.

Silva, V.A.; Andrade, L.D. \& Albuquerque, U.P. 2006. Revising the Cultural Significance Index: The case of the Fulni-o in northeastern Brazil. Field Methods 18: 98-108.

Silva, A.L.; Tamashiro, J. \& Begossi, A. 2007a. Ethnobotany of riverine populations from the Rio Negro, Amazonia (Brazil). Journal of Ethnobiology 27: 46-72.

Silva, E.M.; Souza, J.N.S.; Rogez, H.; Rees, J.F. \& Larondelle, Y. 2007b. Antioxidant activities and polyphenolic contents of fifteen selected plant species from the Amazonian region. Food Chemistry 101: 1012-1018.

Silva Filho, D.F.; Noda, H.; Yuyama, K.; Yuyama, L.K.O.; Aguiar, J.P.L. \& Machado, F.M. 2003. Cubiu (Solanum sessiliflorum Dunal): An Amazonian native medicinal plant in process of selection for cultivation in Manaus, Amazonas, Brazil. Revista Brasileira de Plantas Medicinais 5: 65-70.

Silva Filho, D.F.; Yuyama, L.K.O.; Aguiar, J.P.L.; Oliveira, M.C. \& Martins, L.H.P. 2005. Caracterização e avaliação do potencial agronômico e nutricional de etnovariedades de cubiu (Solanum sessiliflorum Dunal) da Amazônia. Acta Amazonica 35: 399-406.

Simone, C.; Lima, M.I.S.; Nivaldo, N. \& Marques, J.G.W. 2000. Plantas medicinais relatadas pela comunidade residente na EstaçaPo Ecoloìgica de Jataiì, Municiìpio de Luisì Antonio/SP: Uma abordagem etnobotânica. Revista Brasileira de Plantas Medicinais 3: 51-60.

Siqueira, S.J. \& Josafa, C. 2001. A etnobotânica no contexto das transformações sócio-culturais no município de Pirenópolis, Goiás: Desafios para o desenvolvimento sustentável da região. Pesquisas Botânicas 51: 157-167

Soares, E.L.C.; Vendruscolo, G.S.; Eisinger, S.M. \& Zaìchia, R.A. 2004. Estudo etnobotânico do uso dos recursos vegetais em SaPo JoaPo do Polesine, RS, Brasil, no perì̀odo de Outubro de 1999 a Junho de 2001. I - Origem e fluxo do conhecimento. Revista Brasileira de Plantas Medicinais 6: 69-95.

Souza, C.D. \& Felfili, J.M. 2003. Ethnobotany of the cerrado sensu stricto at the Horta Farm, Cavalcante, Goiás State. Boletim do Herbário Ezechias Paulo Heringer 12: 57-71.

Souza, C.D. \& Felfili, J.M. 2006. The utilization of medicinal plants in the region of Alto Paraíso of Goiás, GO, Brazil. Acta Botanica Brasilica 20: 135-142.

Sousa, N.R.; Rodrigues, D.P.; Clement, C.R.; Nagão, E.O. \& AstolfiFilho, S. 2001. Discriminação de raças primitivas de pupunha (Bactris gasipaes) na Amazônia Brasileira por meio de marcadores moleculares (RAPDs). Acta Amazonica 31: 539-545.

Souza, G.C.; Haas, A.P.S.; von Poser, G.L. \& Elisabetsky, E. 2004a. Farmácias caseiras comunitárias do município de Maquiné (RS): uma avaliação etnofarmacológica. Revista Brasileira de Plantas Medicinais 6: 83-91.

Souza, G.C.; Haas A.P.S.; von Poser, G.L.; Schapoval; E.E.S. \& Elisabetsky, E. 2004b. Ethnopharmacological studies of antimicrobial remedies in the south of Brazil. Journal of Ethnopharmacology 90: 135-143.

Souza, G.C.; Kubo, R.; Guimarães, L. \& Elisabetsky, E. 2006. An ethnobiological assessment of Rumohra adiantiformis (samambaia-preta) extractivism in Southern Brazil. Biodiversity and Conservation 15: 2737-2746.

Stehmann, J.R. \& Brandão, M.G.L. 1995. Medicinal plants of Lavras Novas (Minas Gerais, Brazil). Fitoterapia 66: 515-520.

Teixeira, C.C.; Fuchs, F.D.; Blotta, R.M.; Costa, A.P.; Mussnich, D.G. \& Ranquetat, G.G. 1992. Plants employed in the treatment of diabetes mellitus: results of an ethnopharmacological survey in Porto Alegre, Brazil. Fitoterapia 63: 320-322.

Teixeira, C.C.; Pinto, L.P.; Kessler, F.H.P.; Paixão, L.Q.; Miura, C.S.; Guimarães, M.S.; Miura, M.S.; Gastaldo, G.J. \& Fuchs, F.D. 1998. Is the decoction of mango leaves an antihyperglycemic tea? Fitoterapia 69: 165-168.

Toledo, V.M. 1995. New paradigms for a new ethnobotany: reflections on the case of México. Pp. 75-88. In: R.E. Schultes \& S.V. Reis. Ethnobotany: evolution of a discipline. Cambridge, Timber Press: Portland.

Tuxill, J. \& Nabhan, G.P. 2001. People, plants and protected areas. A guide to in situ management. London, Earthscan.

Vendruscolo, G.S.; Simões, C.M.O. \& Mentz, L. 2005a. Etnobotânica no Rio Grande do Sul: Análise comparativa entre o conhecimento original e atual sobre as plantas medicinais nativas. Pesquisas Botânica 56: 285-320.

Vendruscolo, G.S.; Soares, E.L.C.; Eisinger, S.M. \& Zachia, R.A. 2005b. Estudo etnobotânico do uso dos recursos vegetais em SaPo JoaPo do Polesine-RS, no periìodo de outubro de 1999 a junho de 2001 - II - Etnotaxonomia: Criteìrios taxonômicos e classificaçaPo folk. Revista Brasileira de Plantas Medicinais 7: 44-72.

Vendruscolo, G.S. \& Mentz, L.A. 2006. Study of use citations agreement and importance of medicinal used species and families to the community of Ponta Grossa neighborhood, Porto Alegre, Rio Grande do Sul State, Brazil. Acta Botanica Brasilica 20: 367-382.

Vieira, R.F. \& Skorupa, L.A. 1993. Brazilian medicinal plants gene bank. Acta Horticulturae 330: 51-58.

Voeks, R.A. 2007. Are women reservoirs of traditional plant knowledge? Gender, ethnobotany and globalization in northeast Brazil. Singapore Journal of Tropical Geography 28: 7-20.

Voeks, R.A. \& Leony, A. 2004. Forgetting the forest: Assessing medicinal plant erosion in eastern Brazil. Economic Botany 58(Suppl.): 294-306.

Zachia, R.A. \& Irgang, B.E. 2004. A família Annonaceae no Estado do Rio Grande do Sul, Brasil. Pesquisas Botânica 55: 7-127. 